\title{
Monoester-Diterpene Aconitum Alkaloid Metabolism in Human Liver Microsomes: Predominant Role of CYP3A4 and CYP3A5
}

\author{
Ling Ye, ${ }^{1}$ Xiao-Shan Yang, ${ }^{1}$ Lin-lin Lu, ${ }^{1}$ Wei-Ying Chen, ${ }^{1}$ Shan Zeng, ${ }^{1}$ Tong-Meng Yan, \\ Ling-Na Dong, ${ }^{1}$ Xiao-Juan Peng, ${ }^{1}$ Jian Shi, ${ }^{1}$ and Zhong-Qiu Liu ${ }^{1,2}$ \\ ${ }^{1}$ Department of Pharmaceutics, School of Pharmaceutical Sciences, Southern Medical University, Guangzhou, \\ Guangdong 510515, China \\ ${ }^{2}$ International Institute for Translational Chinese Medicine, Guangzhou University of Chinese Medicine, Guangzhou, \\ Guangdong 510006, China \\ Correspondence should be addressed to Zhong-Qiu Liu; liuzq@smu.edu.cn
}

Received 26 March 2013; Revised 23 May 2013; Accepted 23 May 2013

Academic Editor: Gerhard Litscher

Copyright (C) 2013 Ling Ye et al. This is an open access article distributed under the Creative Commons Attribution License, which permits unrestricted use, distribution, and reproduction in any medium, provided the original work is properly cited.

\begin{abstract}
Aconitum, widely used to treat rheumatoid arthritis for thousands of years, is a toxic herb that can frequently cause fatal cardiac poisoning. Aconitum toxicity could be decreased by properly hydrolyzing diester-diterpene alkaloids into monoester-diterpene alkaloids. Monoester-diterpene alkaloids, including benzoylaconine (BAC), benzoylmesaconine (BMA), and benzoylhypaconine (BHA), are the primary active and toxic constituents of processed Aconitum. Cytochrome P450 (CYP) enzymes protect the human body by functioning as the defense line that limits the invasion of toxicants. Our purposes were to identify the CYP metabolites of BAC, BMA, and BHA in human liver microsomes and to distinguish which isozymes are responsible for their metabolism through the use of chemical inhibitors, monoclonal antibodies, and cDNA-expressed CYP enzyme. High-resolution mass spectrometry was used to characterize the metabolites. A total of 7, 8, and 9 metabolites were detected for BAC, BMA, and BHA, respectively. The main metabolic pathways were demethylation, dehydrogenation, demethylation-dehydrogenation, hydroxylation and didemethylation, which produced less toxic metabolites by decomposing the group responsible for the toxicity of the parent compound. Taken together, the results of the chemical inhibitors, monoclonal antibodies, and cDNA-expressed CYP enzymes experiments demonstrated that CYP3A4 and CYP3A5 have essential functions in the metabolism of BAC, BMA, and BHA.
\end{abstract}

\section{Introduction}

Aconitum has been used as an essential drug in China and in other East Asian countries for centuries owing to its extremely excellent effect against rheumatosis and rheumatoid arthritis $[1,2]$. It was reported that among 500 known prescriptions, the frequency of use of the Aconitum is $13.20 \%$, ranked 9 [3]. Nevertheless, Aconitum is a toxic herb that can cause fatal cardiac poisoning [4-6] and is reportedly involved in suicidal and homicidal attempts $[6,7]$. Since the therapeutic dose of Aconitum is very close to its toxic dose, its poisoning incidents are not uncommon. According to the literature data, in 188 cases of patients with Aconitum, 111 patients had varying degrees of toxic reactions [3]. The toxicological mechanism of Aconitum is widely recognized to be associated with voltage-dependent $\mathrm{Na}^{+}$channels [8] .
So the death of patients suffering from Aconitum toxicities always is cardiac arrest or respiratory insufficiency. Up to now, there is no effective antidote to Aconitum intoxication. The initial toxic signs are gastrointestinal including nausea, vomiting, and diarrhea. This is followed by a sensation of burning, tingling, and numbness in the mouth and face, and of burning in the abdomen $[9,10]$.

Therefore, prevention of Aconitum toxicity is a key issue for its safe application. Efflux transporters and metabolic enzymes act as the human body's first line of protection by limiting the invasion of toxicants [11]. Investigation on the roles of efflux transporters and metabolic enzymes in Aconitum is meaningful.

Aconitum contains high amounts of three highly toxic diester-diterpene alkaloids (DDAs), namely, aconitine (AC), mesaconitine (MA), and hypaconitine (HA) [12]. Selling 
unprocessed Aconitum is forbidden on the Chinese market. With proper processing, AC, MA, and HA become exposed to abundant hydrolysis, transforming them into less toxic monoester-diterpene alkaloids (MDAs), namely, benzoylaconine (BAC), benzoylmesaconine (BMA), and benzoylhypaconine (BHA) [12].

MDAs are the primary active and toxic constituents of processed Aconitum. The alkaloid content in processed Aconitum is reportedly as follows: $\mathrm{BMA}>\mathrm{HA}>\mathrm{BAC}>\mathrm{MA}>$ AC [13]. Aside from DDAs, MDAs are detectable in human serum and urine after oral intake of Aconitum extract [14]. Moreover, MDAs are evident in the plasma, liver, and kidney after the administration of DDAs, indicating that DDAs are chemically and biologically hydrolyzed into MDAs $[2,15]$. BMA could reportedly recover the impaired resistance of thermally injured mice infected by HSV type 1 or Candida albicans [16]. The toxicity of MDAs is much less than those of DDAs (the human lethal dose is $1 \mathrm{mg}$ to $4 \mathrm{mg}$ ) [17, 18]. However, the toxic reaction will still occur in the event of excessive MDA absorption [12]. Frequent cases of poisoning after the intake of processed Aconitum are encountered in clinics.

Previous studies suggested that DDAs could be metabolized into less toxic products by CYP enzymes (the major function of CYP3A) in the human liver microsomes [19-21]. The main metabolic pathways of DDAs include demethylation, dehydrogenation, hydroxylation, and didemethylation [19-21]. Efflux transporters such as P-glycoprotein, breast cancer resistance protein, and multidrug resistanceassociated protein 2 were involved in the transport of DDAs [11]. Thus, the toxicity of DDAs is reduced by the effect of metabolic enzymes and efflux transporters [11, 19-21]. We investigated the role of efflux transporters in the transport of MDAs and found that efflux transporters did not mediate their transport [11]. This result indicates that the invasion of MDAs could not be limited by efflux transporters. Efflux transporters and metabolic enzymes act as the human body's first line of protection by limiting the invasion of toxicants [11]. However, thus far, the effect of metabolic enzymes on MDAs is unknown. Therefore, investigating the metabolic mechanism of MDAs for clinical practice is significant.

We tested phase I and phase II metabolism of MDAs (BAC, BMA, and BHA) by human liver microsomes in preliminary experiments. No phase II metabolites but several oxidative metabolites of BAC, BMA, or BHA were detected in the reaction systems. This study aims to identify the CYP metabolites of BAC, BMA, and BHA in human liver microsomes as well as the CYP isozymes responsible for their metabolism. High-resolution mass spectrometry was used to characterize the structures of their metabolites. Moreover, chemical inhibitors of specific CYP enzymes, CYP-specific inhibitory monoclonal antibodies, and cDNA-expressed CYP enzymes (CYP1A2, 2C8, 2C9, 2C19, 2D6, 2E1, 3A4, and $3 A 5)$ were used to verify which isozymes mediate in the metabolism of the CYP metabolites. These results on MDAs metabolism provide important data for the safe clinical use of processed Aconitum.

\section{Materials and Methods}

2.1. Materials. BAC, BMA, BHA, and testosterone (as internal standard) (purity $>98 \%$ ) were purchased from Nanjing Zelang Medical Technology Co., Ltd. (Nanjing, China). Pooled human liver microsomes (HLMs, $20 \mathrm{mg} / \mathrm{mL}$, including reductase), $\beta$-nicotinamide adenine dinucleotide phosphate (NADP), glucose-6-phosphate (6-P-G), and glucose6-phosphate dehydrogenase $(\mathrm{PDH})$ were purchased from BD Gentest Corp. (Woburn, MA, USA). cDNA-expressed CYP enzymes (CYP1A2, 2C8, 2C9, 2C19, 2D6, 2E1, 3A4, and 3A5), chemical inhibitors (fluvoxamine maleate, quercetin, amiodarone, omeprazole, quinidine, diethyldithiocarbamic acid, and ketoconazole) [22-27], and inhibitory monoclonal antibodies were also obtained from BD Gentest Corp. (Woburn, MA, USA). The monoclonal antibodies (mAbs, $10 \mathrm{mg} / \mathrm{mL}$ protein content) used were mAb-1A2 (anti-human CYP1A2), mAb-2C8 (anti-human CYP2C8), mAb-2C19 (anti-human CYP2C19), mAb-2D6 (anti-human CYP2D6), mAb-2E1 (anti-human CYP2E1), and mAb-3A4/5 (anti-human CYP3A4/5). Other chemicals, generally of reagent grade or better, were used as received.

2.2. Phase I Metabolism of BAC, BMA, and BHA in HLMs. A typical incubation system contained potassium phosphate (50 mM, pH 7.4), NADP (1.55 mM), 6-P-G (3.3 mM), $\mathrm{MgCl}_{2}$ (3.3 mM), PDH (0.4 U/mL), HLMs (0.4 mg protein $/ \mathrm{mL})$, and BAC, BMA, or BHA $(10 \mu \mathrm{M})$ in a total volume of $500 \mu \mathrm{L}$. After a $5 \mathrm{~min}$ preincubation at $37^{\circ} \mathrm{C}$, the reactions were started by adding NADPH [28]. Incubations were carried out for $90 \mathrm{~min}$ in a shaking water bath $(150 \mathrm{rpm})$ at $37^{\circ} \mathrm{C}$ and were stopped by the addition of $4 \mathrm{~mL}$ ice-cold dichloromethane and $100 \mu \mathrm{L}$ testosterone (200 $\mathrm{nM}$, used as an internal standard). The parent drug and its metabolites were extracted by vortexing for $8 \mathrm{~min}$, after which they were centrifuged for $15 \mathrm{~min}$ at $1000 \mathrm{rpm}$. The supernatant was drawn into another tube and evaporated to dryness. The residue was dissolved with $50 \%$ methanol in water $(125 \mu \mathrm{L})$ and analyzed by liquid chromatography with tandem mass spectrometry detection (LC-MS/MS). Control incubations were conducted in the absence of a NADPH-regenerating system.

To determine the protein concentration-dependent specificity of the enzyme, HLMs at concentrations of 0.2 , 0.4 , and $0.8 \mathrm{mg} / \mathrm{mL}$ were incubated at $37^{\circ} \mathrm{C}$ for $90 \mathrm{~min}$ in the above-described reaction system, respectively. To determine the time-dependent specificity, the reactions were processed for $30,60,90$, and $120 \mathrm{~min}$ at $37^{\circ} \mathrm{C}$ in the reaction system, respectively. To determine the substrate concentrationdependent specificity, substrates at concentrations of 2.5, $5,10,15$, and $20 \mu \mathrm{M}$ were incubated in HLMs at $37^{\circ} \mathrm{C}$ for $120 \mathrm{~min}$, respectively. Each experiment was performed using three samples.

2.3. Effect of Chemical Inhibitors on the Metabolism of BAC, $B M A$, and BHA in HLMs. The selective inhibitors were chosen based on FDA recommendation, and previous reports, and are listed as follows: fluvoxamine maleate for CYP1A2, quercetin for CYP2C8, amiodarone for CYP2C9, omeprazole 
for CYP2C19, quinidine for CYP2D6, diethyldithiocarbamic acid for CYP2E1 and ketoconazole for CYP3A4/5 [22-27]. To obtain the maximum possible inhibition for each of the isoforms, the final inhibitor concentrations in the reaction mixtures were much higher than the reported Ki values. The concentration of each inhibitor was $5 \mu \mathrm{M}$. The inhibitors were preincubated with all incubation mixtures for $5 \mathrm{~min}$ at $37^{\circ} \mathrm{C}$ before the initiation of the reaction by the addition of BAC, BMA, or BHA [20]. The mixture was then incubated for $120 \mathrm{~min}$ at $37^{\circ} \mathrm{C}$. A comparison was made between the incubations of samples with and without the inhibitors. All incubations were carried out in triplicate.

2.4. Effect of $m A$ bs on the Metabolism of BAC, BMA, and BHA in HLMs. Immunoinhibition studies were conducted by incubating HLMs with various amounts of human selective mAbs (mAb-1A2, mAb-2C8, mAb-2C19, mAb-2D6, mAb$2 \mathrm{E} 1$, and $\mathrm{mAb}-3 \mathrm{~A} 4 / 5)$. MAbs $(10 \mu \mathrm{L})$ were incubated with HLMs for 15 min on ice before the addition of the parent drug (BAC, BMA, or BHA, $10 \mu \mathrm{M}$ ) and the NADPH-regenerating system [21]. The mixture was incubated at $37^{\circ} \mathrm{C}$ for $120 \mathrm{~min}$. As a control, comparable incubations were performed with HLMs and Tris buffer $(25 \mathrm{mM})$. All incubations were conducted in triplicate.

2.5. Phase I Metabolism of BAC, BMA, and BHA in CDNAExpressed CYP Enzymes. The incubation procedures of BAC, BMA, or BHA in CDNA-expressed CYP enzymes were performed as described for HLMs, except that the concentration of the enzyme used was $40 \mathrm{pmol} / \mathrm{mL}[21,29]$. The isozymes used in this study included CYP 1A2, 2C8, 2C9, 2C19, 2D6, 2E1, 3A4, and 3A5. All incubations were performed in triplicate.

2.6. Identification and Quantitation of the Metabolites by LC$M S / M S$. A quadrupole time of flight tandem mass spectrometer (Bruker, Daltonics, USA) was used to calculate the molecular weight of the metabolites, which could be deduced through their molecular formulas. The quantitative analysis procedure was as follows. The UPLC conditions were system, Waters Acquity; column, Acquity UPLC BEH C18 column $(50 \times 2.1 \mathrm{~mm}, 1.7 \mu \mathrm{m}$, Waters, Milford, MA, USA); mobile phase A: $0.1 \%(\mathrm{v} / \mathrm{v})$ formic acid in water; mobile phase $\mathrm{B}$ : $100 \%$ acetonitrile; gradient, $0 \mathrm{~min}$ to $0.5 \mathrm{~min}$ at 2 to $2 \% \mathrm{~B}$, $0.5 \mathrm{~min}$ to $2 \mathrm{~min}$ at $2 \%$ to $20 \% \mathrm{~B}, 2 \mathrm{~min}$ to $4 \mathrm{~min}$ at $20 \%$ to $40 \% \mathrm{~B}, 4 \mathrm{~min}$ to $6.5 \mathrm{~min}$ at $40 \%$ to $70 \% \mathrm{~B}$, and $6 \mathrm{~min}$ to $7 \mathrm{~min}$ at $70 \%$ to $2 \% \mathrm{~B}$; flow rate, $0.35 \mathrm{~mL} / \mathrm{min}$; column temperature, $50^{\circ} \mathrm{C}$; and injection volume, $10 \mu \mathrm{L}$. The MS/MS detector used was a quadrupole tandem mass spectrometer (Waters, USA). Samples were analyzed using electrospray ionization in the positive model. The main working parameters were set as follows: capillary voltage, $3 \mathrm{kV}$; cone voltage, $50 \mathrm{~V}$; collision voltage, $30 \mathrm{~V}$; source temperature, $120^{\circ} \mathrm{C}$; desolvation temperature, $500^{\circ} \mathrm{C}$; desolvation gas flow, $600 \mathrm{~L} / \mathrm{Hr}$; cone gas flow, $50 \mathrm{~L} / \mathrm{Hr}$; and collision gas glow, $0.20 \mathrm{~mL} / \mathrm{min}$. Data were collected and analyzed by Waters Quantify software (Masslynx 4.1, Waters, USA).
2.7. Data Analysis. Data are expressed as mean \pm SD. Oneway analysis of variance (ANOVA) with or without TukeyKramer multiple comparisons (post hoc) tests were used to evaluate statistical differences. Differences were considered significant when $P$ values were less than 0.05 .

\section{Results}

3.1. Identification of the BAC, BMA, and BHA Metabolites in HLMs. To determine the best conditions for incubation, we optimized the incubation time, protein concentration, and substrate concentration. According to the largest formation of metabolites, the final protein concentration was selected to be $0.4 \mathrm{mg} / \mathrm{mL}$ and the appropriate incubation time was $120 \mathrm{~min}$. Meanwhile, for the substrate concentration-dependent study, the formations of BAC, BMA, and BHA metabolites were all linear at concentrations of $2.5 \mu \mathrm{M}$ to $20 \mu \mathrm{M}$, indicating that the concentration of $10 \mu \mathrm{M}$ BAC, BMA, or BHA that we chose for this study was suitable for the experiments. Compared with the negative control (without NADPH-regenerating system), a total of 7 BAC metabolites, 8 BMA metabolites and 9 BHA metabolites were found in the HLMs along with the NADPH-regenerating system (Figure 1). The metabolites were identified by the retention times, the chromatographic behaviors, and characteristic mass spectrometric fragmentation features, which are summarized in Table 1.

3.2. BAC Metabolites in HLMs. BAC, eluted at $3.77 \mathrm{~min}$, possessed a pseudo-molecule ion $[\mathrm{M}+\mathrm{H}]^{+}$at $m / z$ 604.3109, which corresponded to the smart molecular formula of $\mathrm{C}_{32} \mathrm{H}_{45} \mathrm{NO}_{10}$. The $\mathrm{MS}^{2}$ spectrum of $[\mathrm{M}+\mathrm{H}]^{+}$provided a number of characteristic fragment ions at $m / z 586,572,554$, 540,522 , and 508.

3.3. BAC Metabolites M1 and M2. M1 and M2 were eluted at 3.38 and $3.50 \mathrm{~min}$, respectively. M1 and M2 showed a pseudomolecule ion $[\mathrm{M}+\mathrm{H}]^{+}$at $\mathrm{m} / z$ 602.2951, which confirmed the smart molecular formula $\left(\mathrm{C}_{32} \mathrm{H}_{43} \mathrm{NO}_{10}\right)$, indicating a loss of $2 \mathrm{Da}(2 \mathrm{H})$ from BAC, displaying that they were dehydrogenated metabolites of BAC. The $\mathrm{MS}^{2}$ spectrum of $\mathrm{M1}$ and M2 showed fragmentation ions at $m / z 584,570,552,538$, and 506, which were also $2 \mathrm{Da}$ lower than the characteristic fragment ions of BAC. Thus, M1 and M2 metabolites were identified as dehydrogenation-BAC. $\mathrm{H}_{2}$ group could be taken off from positions 2,12 , and 15 . Therefore, the exact positions of dehydrogenation were not confirmed.

3.4. BAC Metabolite M3. M3 had a retention time of $3.08 \mathrm{~min}$, and its pseudo-molecule ion $[\mathrm{M}+\mathrm{H}]^{+}$was at $\mathrm{m} / z$ 588.2791. Thus, the smart molecular formula was calculated to be $\mathrm{C}_{31} \mathrm{H}_{41} \mathrm{NO}_{10}$, which had an observed loss of $\mathrm{CH}_{4}$ group compared with BAC. An MS/MS scan of M3 generated fragment ions at $m / z 570,556,538,524,506$, and 492, all of which were $16 \mathrm{Da}$ lower than the fragment ions of the parent molecule. Therefore, M3 was identified as demethylateddehydrogenated BAC metabolite. Metabolism may have occurred either by demethylation and then dehydrogenation or by dehydrogenation and then demethylation. Another 

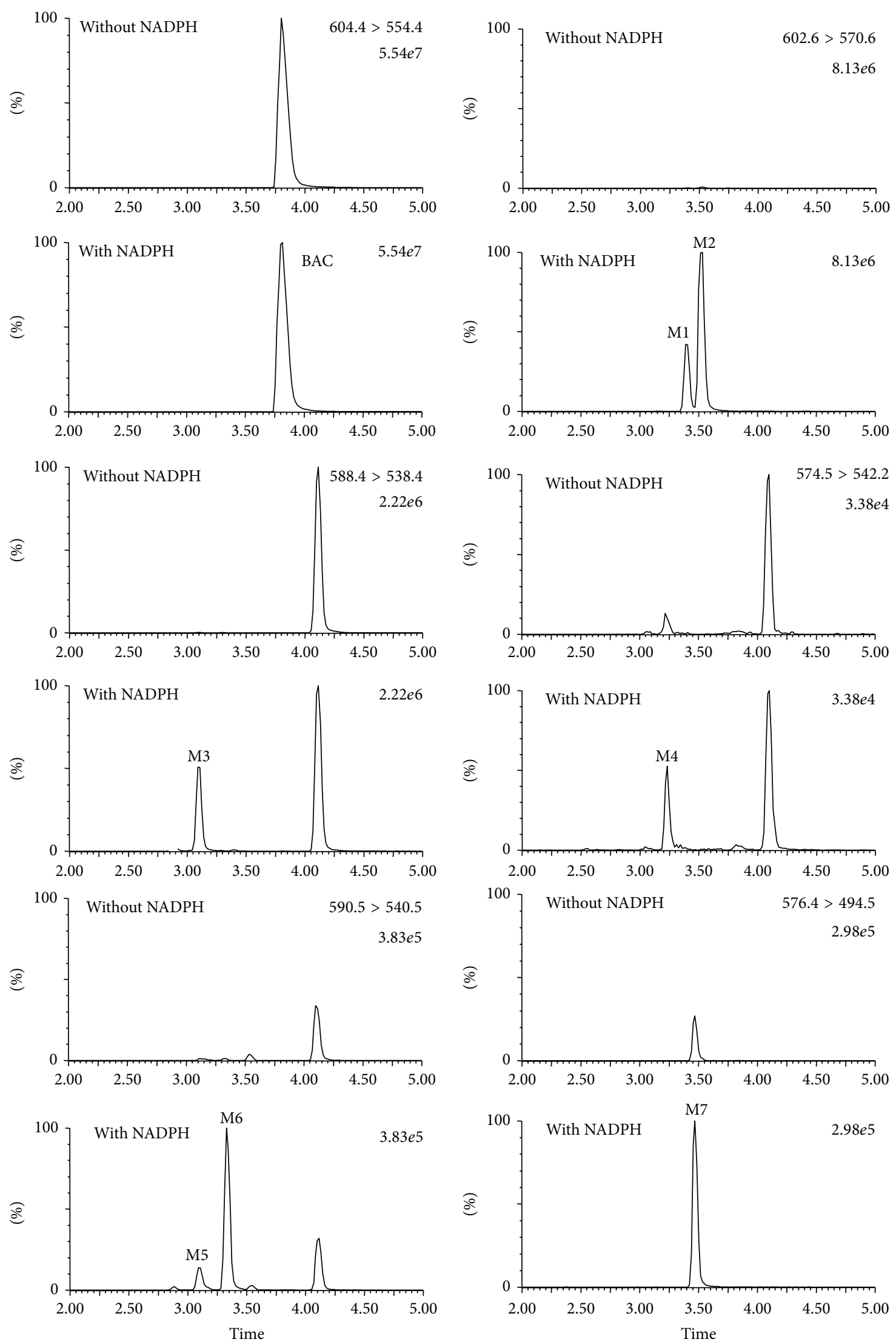

(a)

FIgURe 1: Continued. 

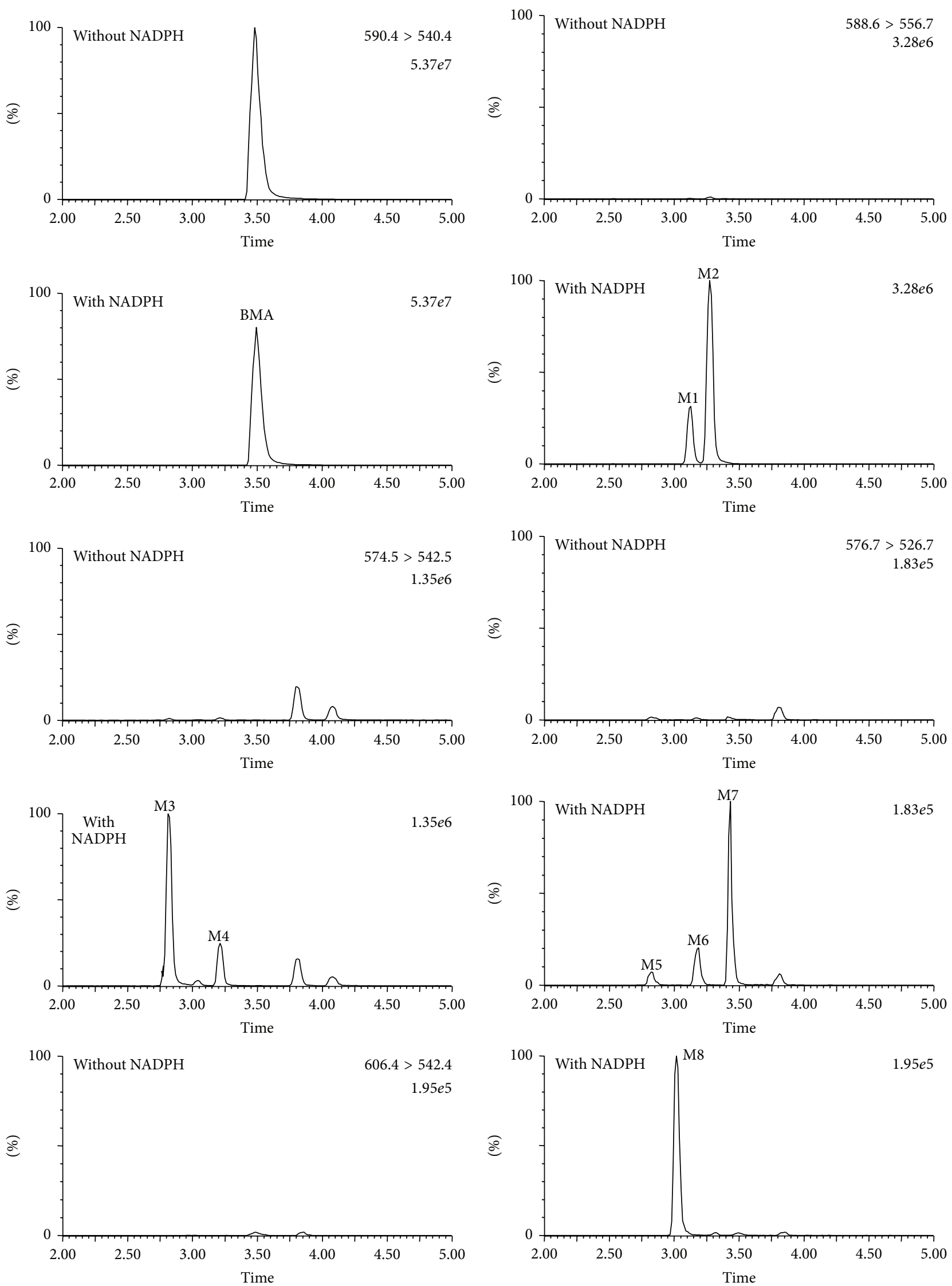

(b)

Figure 1: Continued. 

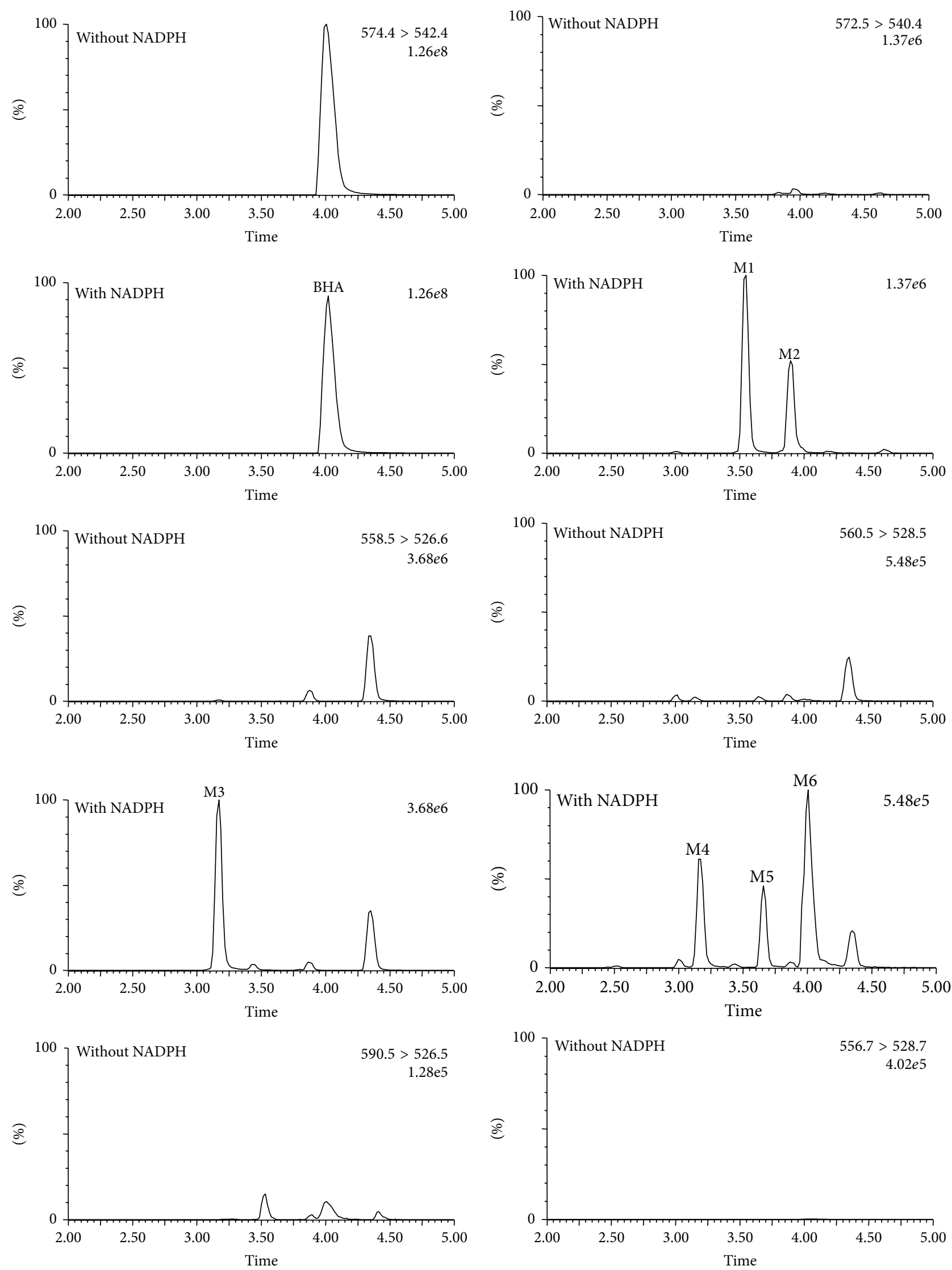

(c)

FIgUre 1: Continued. 

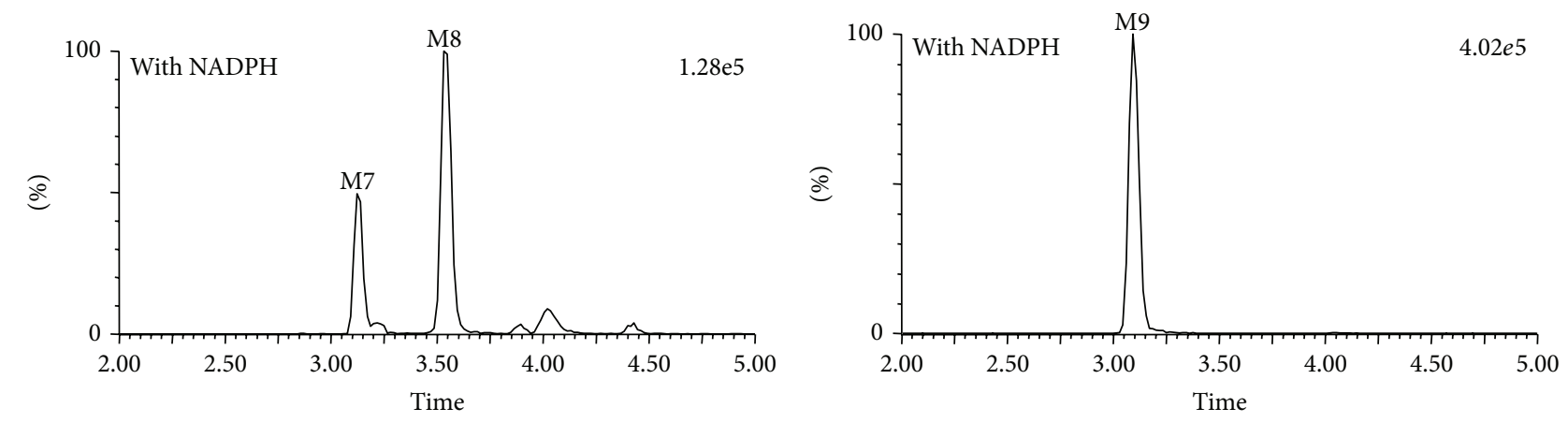

(c)

FIGURE 1: Representative selective ion current chromatograms of the BAC (a), BMA (b), and BHA (c) metabolites in HLMs incubated with $10 \mu \mathrm{M}$ of the parent compound for $120 \mathrm{~min}$ at $37^{\circ} \mathrm{C}$. A total of 7,8 , and 9 metabolites were observed for BAC, BMA, and BHA after incubation with HLMs and NADPH, respectively.

dubious peak existed in the same reaction channel, which was eluted at $4.10 \mathrm{~min}$. Its smart molecular formula was calculated to be $\mathrm{C}_{32} \mathrm{H}_{45} \mathrm{NO}_{9}$, which did not have similar structure with BAC. Meanwhile, this peak could not only be detected with NADPH-regenerating system, but also be detected without NADPH-regenerating system (negative control). Therefore, the peak eluted at $4.10 \mathrm{~min}$ was not the CYP metabolite of BAC. We speculated that it was just the endogenous substance of the phase I metabolic system.

3.5. BAC Metabolite M4. The M4 peak eluted at $3.20 \mathrm{~min}$ exhibited a pseudo-molecule ion $[\mathrm{M}+\mathrm{H}]^{+}$at $\mathrm{m} / z 574.2791$ $\left(\mathrm{C}_{30} \mathrm{H}_{39} \mathrm{NO}_{10}\right)$, which was $30 \mathrm{Da}\left(\mathrm{C}_{2} \mathrm{H}_{6}\right)$ lower than that of $\mathrm{BAC}$, confirming the smart molecular formula. The $\mathrm{MS}^{2}$ spectrum of M4 displayed fragment ions at $m / z 542,524$, 510,492 , and 478 , and these fragment ions were all $30 \mathrm{Da}$ less than the corresponding fragments generated by BAC. Therefore, M4 was identified as didemethyl-dehydrogen-BAC or deethyl-dehydrogen-BAC. By the way, the peak having a retention time of $4.10 \mathrm{~min}$ was not the CYP metabolite of BAC, because of the peak could not only be detected with NADPH-regenerating system, but also be detected without NADPH-regenerating system (negative control).

3.6. BAC Metabolites M5 and M6. UPLC retention times of 3.08 and $3.31 \mathrm{~min}$ were obtained for M5 and M6, respectively. Their pseudo-molecule ion $[\mathrm{M}+\mathrm{H}]^{+}$was both at $\mathrm{m} / \mathrm{z}$ 590.2940 , and the smart molecular formula was concluded to be $\mathrm{C}_{31} \mathrm{H}_{43} \mathrm{NO}_{10}$, which eliminated a $\mathrm{CH}_{2}$ group from the parent compound. The $\mathrm{MS}^{2}$ spectrum of fragment ions was seen at $m / z 572,558,540,526$ and 508 , which were $14 \mathrm{Da}$ lower than the fragment ions of BAC. Conclusively, M5 and M6 were identified as demethyl-BAC, but the demethylation would occur at positions $1,6,16$, and 18. Similarly, the peak eluted at $4.1 \mathrm{~min}$ was not the CYP metabolite of BAC, because the peak could not only be detected with NADPHregenerating system, but also be detected without NADPHregenerating system (negative control).
3.7. BAC Metabolite M7. M7 exhibited a retention time of $3.45 \mathrm{~min}$ and had an $[\mathrm{M}+\mathrm{H}]^{+}$at $m / z$ 576.2805. The smart molecular formula was confirmed to be $\mathrm{C}_{30} \mathrm{H}_{41} \mathrm{NO}_{10}$. The diagnostic ions at $m / z 558,544,526,512,494$, and 480 were $28 \mathrm{Da}\left(\mathrm{C}_{2} \mathrm{H}_{4}\right)$ lower than the fragment ions in the $\mathrm{MS}^{2}$ spectra of BAC. Taken together, the results suggested that M7 may either be a metabolite of BAC with a loss of ethylation on the nitrogen atom or a didemethyl-BAC.

3.8. BMA Metabolites in HLMs. The peak elution at $3.48 \mathrm{~min}$ corresponded to BMA. BMA exhibited a pseudo-molecule ion $[\mathrm{M}+\mathrm{H}]^{+}$at $m / z 590.2963$ in the full-scan mass spectrum. The smart molecular formula of $\mathrm{C}_{31} \mathrm{H}_{43} \mathrm{NO}_{10}$ was demonstrated, and the $\mathrm{MS}^{2}$ spectrum of $[\mathrm{M}+\mathrm{H}]^{+}$showed fragment ions at $m / z 572,558,540,526$, and 508 .

3.9. BMA Metabolites M1 and M2. M1 and M2 were eluted at 3.11 and $3.27 \mathrm{~min}$, respectively. They showed a pseudomolecule ion $[\mathrm{M}+\mathrm{H}]^{+}$at $m / z 588.2802$, confirming the smart molecular formula of $\mathrm{C}_{31} \mathrm{H}_{41} \mathrm{NO}_{10}$ and a loss of $2 \mathrm{Da}(2 \mathrm{H})$ from BMA. The $\mathrm{MS}^{2}$ spectrum of $\mathrm{M} 1$ and M2 showed fragmentation ions at $m / z 570,556,538$, and 524 , which were also $2 \mathrm{Da}$ lower than the corresponding fragments generated by BMA. Thus, they are dehydrogenated metabolites of BMA. A loss of $\mathrm{H}_{2}$ group could occur in positions 2, 12, and 15, suggesting that the exact positions of dehydrogenation were not confirmed.

3.10. BMA Metabolites M3 and M4. The UPLC retention times of metabolites M3 and M4 were 2.81 and $3.20 \mathrm{~min}$, and their pseudo-molecule ion $[\mathrm{M}+\mathrm{H}]^{+}$was both at $\mathrm{m} / z$ 574.2642. Their smart molecular formula was suggested to be $\mathrm{C}_{30} \mathrm{H}_{39} \mathrm{NO}_{10}$, and a $\mathrm{CH}_{4}$ group was lost compared with BMA. MS/MS scan of M3 and M4 showed fragment ions at $m / z 556,542,524,510$, and 492 , which were 16 Da lower than that of BMA. Therefore, M3 and M4 were identified as demethyl-dehydrogen-BMA. To speak of, the peaks eluted at 3.9 and 4.1 min were not the CYP metabolite of BMA, because these peaks could be detected with or without NADPHregenerating system (negative control). 
TABLE 1: LC-MS ${ }^{\mathrm{n}}$ data of the BAC, BMA, and BHA metabolites in HLMs with NADPH.

\begin{tabular}{|c|c|c|c|c|}
\hline Metabolite & $\begin{array}{c}{[\mathrm{M}+\mathrm{H}]^{+}} \\
(m / z)\end{array}$ & $\begin{array}{c}\text { Smart formula } \\
{[\mathrm{M}]}\end{array}$ & Major fragment ions & Identification \\
\hline BAC & 604.3109 & $\mathrm{C}_{32} \mathrm{H}_{45} \mathrm{NO}_{10}$ & $586,572,554,540,522,508$ & BAC \\
\hline M1 & 602.2951 & $\mathrm{C}_{32} \mathrm{H}_{43} \mathrm{NO}_{10}$ & $584,570,552,538,506$ & Dehydrogen-BAC \\
\hline M2 & 602.2949 & $\mathrm{C}_{32} \mathrm{H}_{43} \mathrm{NO}_{10}$ & $584,570,552,538,506$ & Dehydrogen-BAC \\
\hline M3 & 588.2791 & $\mathrm{C}_{31} \mathrm{H}_{41} \mathrm{NO}_{10}$ & $570,556,538,524,506,492$ & Demethyl-dehydrogen-BAC \\
\hline M4 & 574.2638 & $\mathrm{C}_{30} \mathrm{H}_{39} \mathrm{NO}_{10}$ & $542,524,510,492,478$ & Didemethyl-dehydrogen-BAC/Deethyl-dehydrogen-BAC \\
\hline M5 & 590.2940 & $\mathrm{C}_{31} \mathrm{H}_{43} \mathrm{NO}_{10}$ & $572,558,540,526,508$ & Demethyl-BAC \\
\hline M6 & 590.2944 & $\mathrm{C}_{31} \mathrm{H}_{43} \mathrm{NO}_{10}$ & $572,558,540,526,508$ & Demethyl-BAC \\
\hline M7 & 576.2805 & $\mathrm{C}_{30} \mathrm{H}_{41} \mathrm{NO}_{10}$ & $558,544,526,512,494,480$ & Deethyl-BAC/didemethyl-BAC \\
\hline BMA & 590.2963 & $\mathrm{C}_{31} \mathrm{H}_{43} \mathrm{NO}_{10}$ & $572,558,540,526,508$ & BMA \\
\hline M1 & 588.2802 & $\mathrm{C}_{31} \mathrm{H}_{41} \mathrm{NO}_{10}$ & $570,556,538,524$ & Dehydrogen-BMA \\
\hline M2 & 588.2808 & $\mathrm{C}_{31} \mathrm{H}_{41} \mathrm{NO}_{10}$ & $570,556,538,524$ & Dehydrogen-BMA \\
\hline M3 & 574.2642 & $\mathrm{C}_{30} \mathrm{H}_{39} \mathrm{NO}_{10}$ & $556,542,524,510,492$ & Demethyl-dehydrogen-BMA \\
\hline M4 & 574.2647 & $\mathrm{C}_{30} \mathrm{H}_{39} \mathrm{NO}_{10}$ & $556,542,524,510,492$ & Demethyl-dehydrogen-BMA \\
\hline M5 & 576.2789 & $\mathrm{C}_{30} \mathrm{H}_{41} \mathrm{NO}_{10}$ & $558,544,526,512,494$ & Demethyl-BMA \\
\hline M6 & 576.2790 & $\mathrm{C}_{30} \mathrm{H}_{41} \mathrm{NO}_{10}$ & $558,544,526,512,494$ & Demethyl-BMA \\
\hline M7 & 576.2792 & $\mathrm{C}_{30} \mathrm{H}_{41} \mathrm{NO}_{10}$ & $558,544,526,512,494$ & Demethyl-BMA \\
\hline M8 & 606.2902 & $\mathrm{C}_{30} \mathrm{H}_{43} \mathrm{NO}_{11}$ & $588,574,556,542,524$ & Hydroxyl-BMA \\
\hline BHA & 574.3008 & $\mathrm{C}_{31} \mathrm{H}_{43} \mathrm{NO}_{9}$ & $558,542,524,510,492,478$ & BHA \\
\hline M1 & 572.2857 & $\mathrm{C}_{31} \mathrm{H}_{41} \mathrm{NO}_{9}$ & $556,540,522,508,490,476$ & Dehydrogen-BHA \\
\hline M2 & 572.2862 & $\mathrm{C}_{31} \mathrm{H}_{41} \mathrm{NO}_{9}$ & $556,540,522,508,490,476$ & Dehydrogen-BHA \\
\hline M3 & 558.2709 & $\mathrm{C}_{30} \mathrm{H}_{39} \mathrm{NO}_{9}$ & $542,526,508,494$ & Demethyl-dehydrogen-BHA \\
\hline M4 & 560.2843 & $\mathrm{C}_{30} \mathrm{H}_{41} \mathrm{NO}_{9}$ & $544,528,510,496,464$ & Demethyl-BHA \\
\hline M5 & 560.2855 & $\mathrm{C}_{30} \mathrm{H}_{41} \mathrm{NO}_{9}$ & $544,528,510,496,464$ & Demethyl-BHA \\
\hline M6 & 560.2857 & $\mathrm{C}_{30} \mathrm{H}_{41} \mathrm{NO}_{9}$ & $544,528,510,496,464$ & Demethyl-BHA \\
\hline M7 & 590.2978 & $\mathrm{C}_{31} \mathrm{H}_{43} \mathrm{NO}_{10}$ & $574,558,540,526,508$ & Hydroxyl-BHA \\
\hline M8 & 590.2959 & $\mathrm{C}_{31} \mathrm{H}_{43} \mathrm{NO}_{10}$ & $574,558,540,526,508$ & BMA \\
\hline M9 & 556.2547 & $\mathrm{C}_{30} \mathrm{H}_{37} \mathrm{NO}_{9}$ & $542,528,524,497,465,450$ & Demethyl-didehydrogen-BHA \\
\hline
\end{tabular}

3.11. BMA Metabolites M5, M6, and M7. UPLC retention times of 2.82, 3.16, and $3.41 \mathrm{~min}$ were observed for M5, M6, and $\mathrm{M} 7$, respectively. Their pseudo-molecule ion $[\mathrm{M}+\mathrm{H}]^{+}$ was all at $m / z$ 576.2792, and their smart molecular formula was concluded as $\mathrm{C}_{30} \mathrm{H}_{41} \mathrm{NO}_{10}$, which lacked a $\mathrm{CH}_{2}$ group from the parent compound. The $\mathrm{MS}^{2}$ spectrum of fragment ions was seen at $m / z 558,544,526,512$, and 494 , which were $14 \mathrm{Da}$ lower than the fragment ions of BMA. Therefore, they were estimated to be demethyl-BMA.

3.12. BMA Metabolite M8. M8 had a retention time of $3.01 \mathrm{~min}$ and showed a pseudo-molecule ion $[\mathrm{M}+\mathrm{H}]^{+}$at $\mathrm{m} / \mathrm{z}$ 606.2902. The smart molecular formula was calculated to be $\mathrm{C}_{31} \mathrm{H}_{43} \mathrm{NO}_{11}$. The $\mathrm{MS}^{2}$ spectrum of $[\mathrm{M}+\mathrm{H}]^{+}$provided a number of characteristic fragment ions at $m / z 588,574,556$, 542 , and 524 , which were $16 \mathrm{Da}(\mathrm{O})$ higher than those of BMA. M8 was thus identified as hydroxyl-BMA.

3.13. BHA Metabolites in HLMs. BHA exhibited a retention time of $3.99 \mathrm{~min}$, and its pseudo-molecule ion $[\mathrm{M}+\mathrm{H}]^{+}$ appeared at $m / z 574.3008$, whose smart molecular formula was calculated to be $\mathrm{C}_{31} \mathrm{H}_{43} \mathrm{NO}_{9}$. The $\mathrm{MS}^{2}$ spectrum of $[\mathrm{M}+\mathrm{H}]^{+}$provided a number of fragment ions at $m / z 558,542$, $524,510,492$, and 478 .

3.14. BHA Metabolites M1 and M2. M1 and M2 were eluted at retention times of 3.53 and $3.90 \mathrm{~min}$, respectively. They both showed a molecule ion at $m / z 572.2862$ and a loss of $\mathrm{H}_{2}$ group from BHA. The $\mathrm{MS}^{2}$ scan of the two metabolites included major fragmentation ions at $m / z 556,540,522,508,490$, and 476 , which were $2 \mathrm{Da}$ lower than those of BHA. These results indicated that they were dehydrogen-BHA. Similar to BAC and BMA, the exact positions of dehydrogenation of BHA were not determined.

3.15. BHA Metabolite M3. M3 had a retention time of $3.16 \mathrm{~min}$, and its pseudo-molecule ion $[\mathrm{M}+\mathrm{H}]^{+}$was at $\mathrm{m} / z$ 558.2709. The smart molecular formula was calculated to be $\mathrm{C}_{30} \mathrm{H}_{39} \mathrm{NO}_{9}$, and a loss of $\mathrm{CH}_{4}$ group was observed compared with BHA. MS/MS scan of M3 included fragment ions at $m / z 542,526,508$, and 494 , which were 16 Da lower than the fragment ions of the parent compound. Therefore, M3 

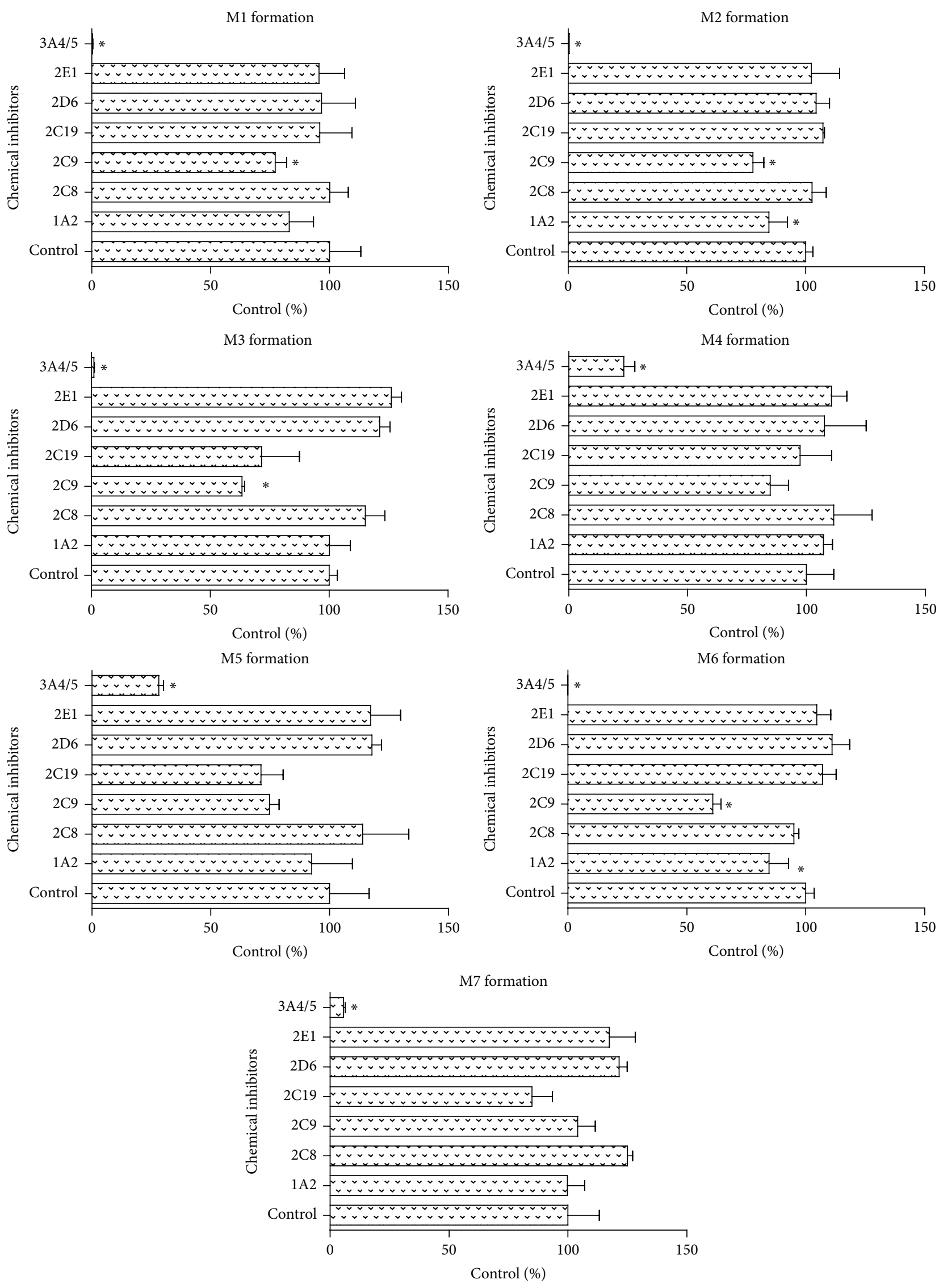

(a)

Figure 2: Continued. 

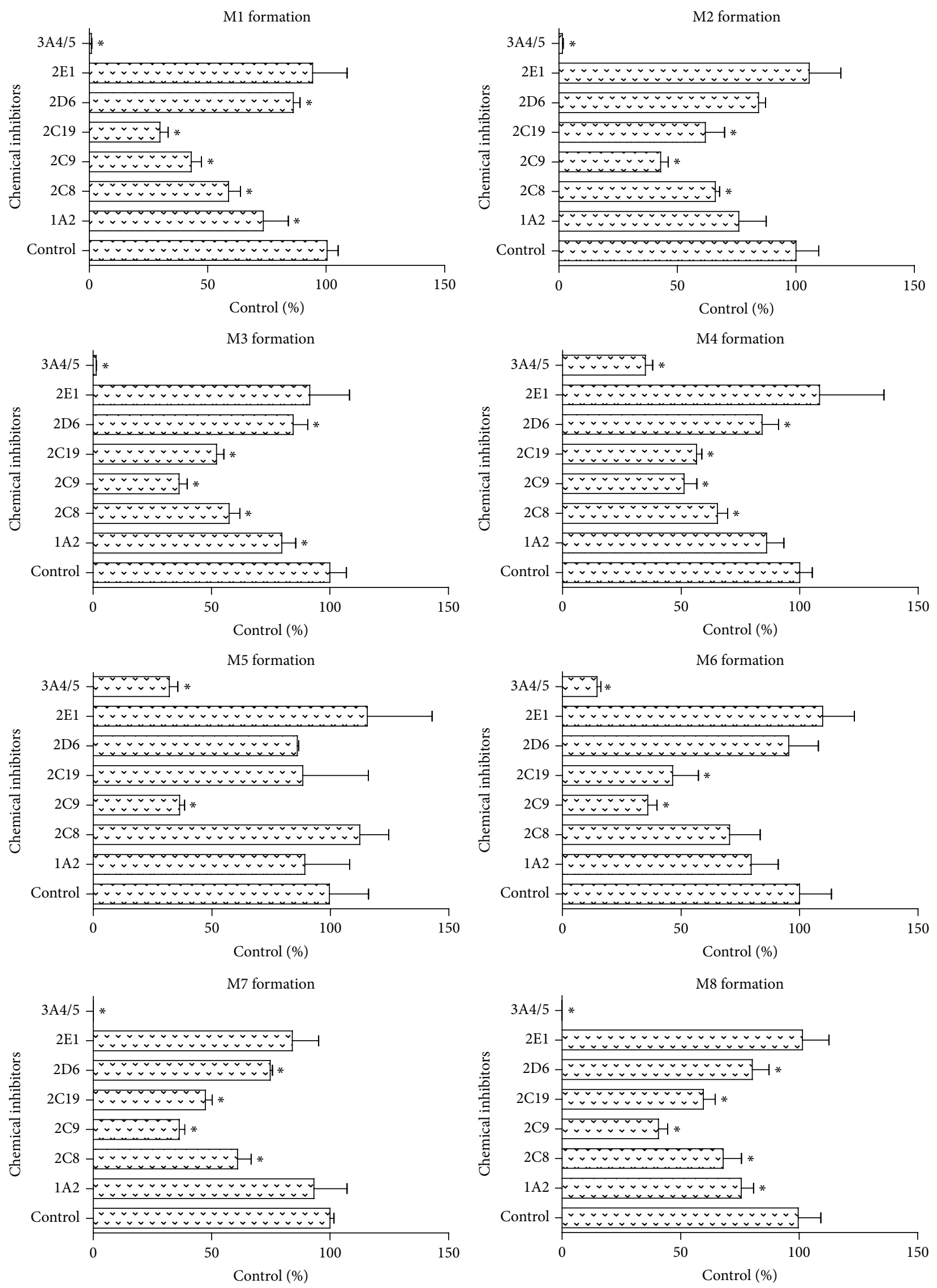

(b)

FIGURE 2: Continued. 

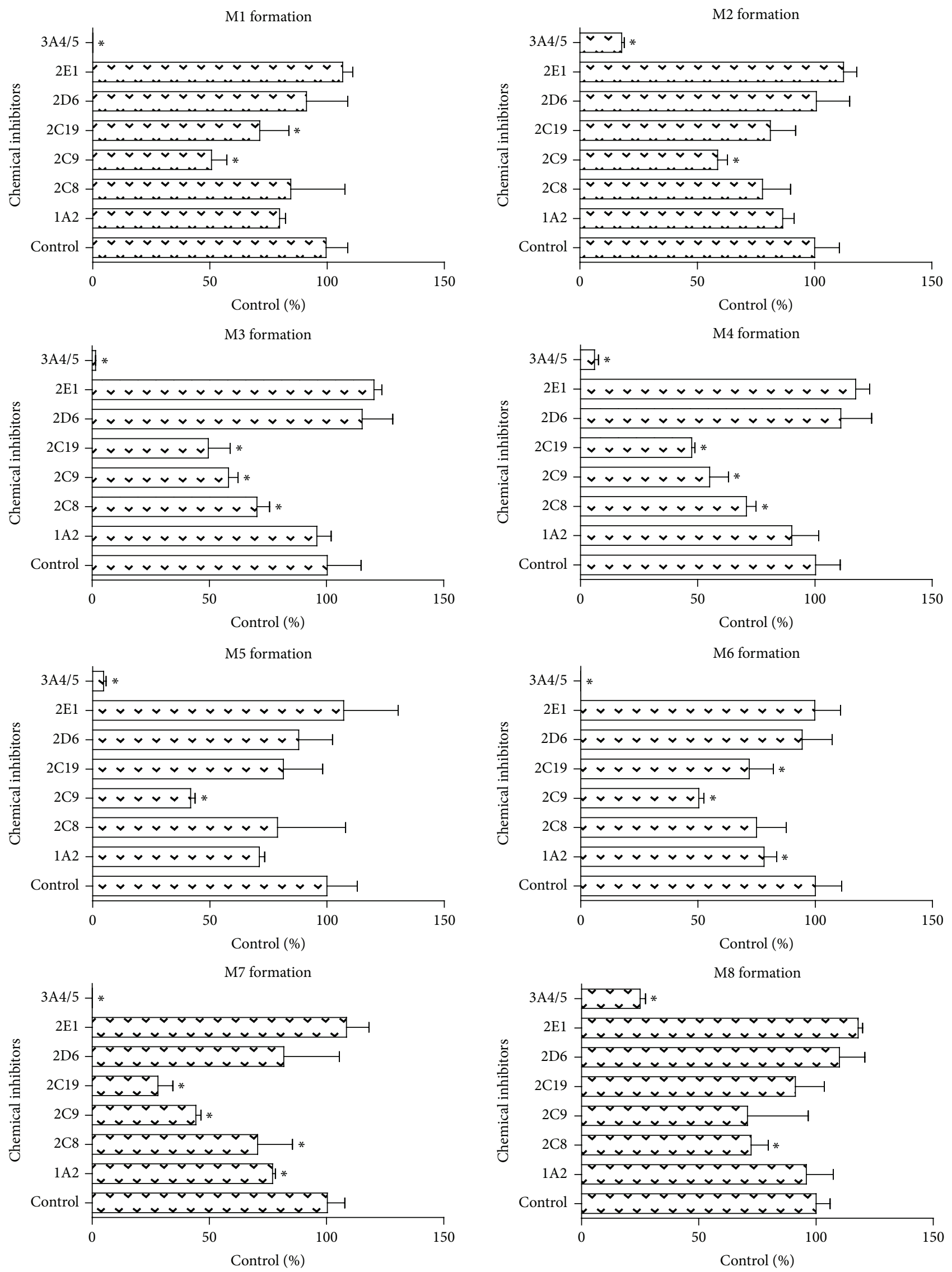

(c)

Figure 2: Continued. 


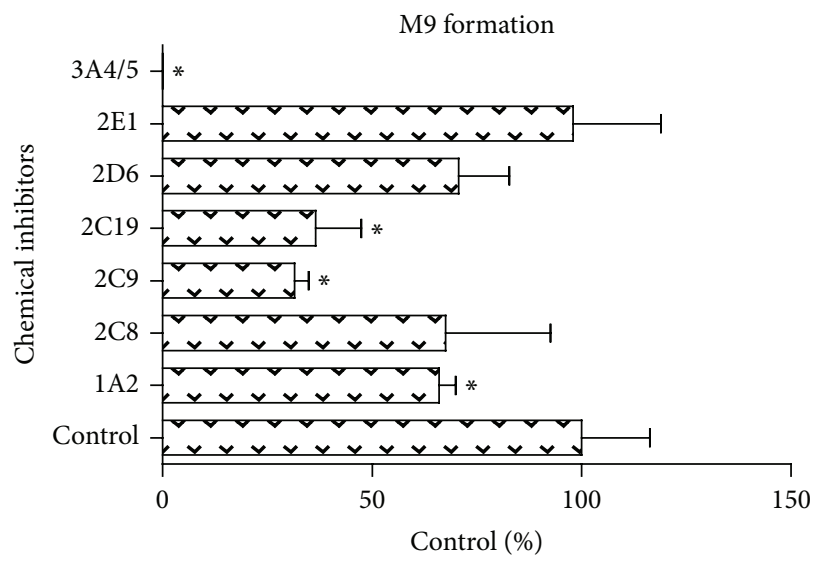

(c)

FIGURE 2: Effects of CYP enzyme chemical inhibitors on BAC (a), BMA (b), and BHA (c) metabolism. BAC, BMA, or BHA (10 $\mu$ M) was incubated with HLMs and NADPH-regenerating system in the presence of $5 \mu \mathrm{M}$ chemical inhibitors for $120 \mathrm{~min}$ at $37^{\circ} \mathrm{C}$. In the control experiments, equivalent amounts of solvent were used in place of the inhibitors. Each column represents the mean of three formation rate determinations for the metabolites, and the error bars represent the standard deviation of the mean. Statistically significant differences compared with the control $(P<0.05)$ are marked with asterisks $(*)$.

was identified as demethyl-dehydrogen-BHA. To speak of, because the peak could be detected with or without NADPHregenerating system (negative control), the peak having a retention time of 4.3 min was not the CYP metabolite of BHA.

3.16. BHA Metabolites M4, M5, and M6. The retention times of M4, M5, and M6 were 3.16, 3.63, and $3.99 \mathrm{~min}$, respectively. Their pseudo-molecule ion $[\mathrm{M}+\mathrm{H}]^{+}$was found at $\mathrm{m} / z$ 560.2855, suggesting that their molecular formula was $\mathrm{C}_{30} \mathrm{H}_{41} \mathrm{NO}_{9}$, which is $14 \mathrm{Da}\left(\mathrm{CH}_{2}\right)$ less than that of BHA. These results indicated that M4, M5, and M6 were demethylated metabolites of BHA.

3.17. BHA Metabolites M7 and M8. M7 and M8 had UPLC retention times of 3.12 and $3.51 \mathrm{~min}$, respectively. They showed a pseudo-molecule ion $[\mathrm{M}+\mathrm{H}]^{+}$at $m / z 590.2978$. The smart molecular formula was determined to be $\mathrm{C}_{31} \mathrm{H}_{43} \mathrm{NO}_{10}$, with an additional $\mathrm{O}$ group compared with the parent compound. The $\mathrm{MS}^{2}$ spectrum of $[\mathrm{M}+\mathrm{H}]^{+}$provided a number of characteristic fragment ions at $m / z 574,558,540,526$, and 508, which were 16 Da higher than those of BHA. M7 and M8 were thus identified as hydroxyl-BMA. M8 was confirmed as BMA using the BMA standard.

3.18. BHA Metabolite M9. Metabolite M9 was eluted at $3.08 \mathrm{~min}$ and showed a pseudo-molecule ion $[\mathrm{M}+\mathrm{H}]^{+}$at $\mathrm{m} / \mathrm{z}$ 556.2547. The smart molecular formula was confirmed to be $\mathrm{C}_{30} \mathrm{H}_{37} \mathrm{NO}_{9}$, which exhibited a loss of a $\mathrm{CH}_{6}$ group compared with the parent compound. MS/MS scan of M9 generated fragment ions at $m / z 542,528,524,497,465$, and 450 . Therefore, M9 may be the demethylated-didehydrogenated metabolite of BHA.

3.19. The Effect of Chemical Inhibitors on the Metabolism of $B A C, B M A$, and BHA in HLMs. Based on the results, we learned that $\mathrm{BAC}, \mathrm{BMA}$, and $\mathrm{BHA}$ were metabolized into several CYP-mediated metabolites in HLMs together with the NADPH-regenerating system. To investigate which CYP isoform is responsible for their metabolism, various CYP enzyme chemical inhibitors were selected in this study.

For BAC (Figure 2(a)), ketoconazole (CYP3A4/5 inhibitor) produced a remarkable effect on the BAC metabolism. The formation of metabolites decreased by at least $70 \%$ compared with that of the control. Moreover, amiodarone (CYP2C9 inhibitor) had a less significant function in the formation of metabolites M1, M2, M3, and M6. Fluvoxamine maleate (CYP1A2 inhibitor) also had a minor effect on M2 and M6. However, the other inhibitors did not inhibit the formation of these seven metabolites. Taken together, CYP3A4/5 exhibited a major contribution to BAC metabolism.

For BMA (Figure 2(b)), compared to the control group, ketoconazole greatly inhibited more than $65 \%$ of the formation of all BMA metabolites. All of the BMA metabolites were also significantly inhibited by the CYP 2C9 inhibitor. The production of M1, M2, M3, M4, M7, and M8 was decreased by the inhibitors of CYP2C8 and CYP2C19. Inhibitory effects on M1, M3, and M8 were observed using fluvoxamine maleate (CYP1A2 inhibitor). Quinidine (CYP2D6 inhibitor) had a negligible function in M1, M3, M4, M7, and M8. Diethyldithiocarbamic acid (CYP2E1 inhibitor) did not exhibit obvious inhibition on all eight metabolites. In general, BMA metabolism was predominantly mediated by CYP $3 \mathrm{~A}$, followed by CYP2C9 and CYP2C19.

For BHA (Figure 2(c)), ketoconazole strongly inhibited the formation of BHA metabolites by more than $75 \%$ compared with the control samples, suggesting that CYP3A4/5 was the major metabolic isozyme for BHA metabolism. The formation of BHA metabolites was significantly inhibited by amiodarone (CYP2C9 inhibitor). Simultaneously, quercetin (CYP2C8 inhibitor) notably reduced the formation of M3, M4, M7, and M8. Omeprazole (CYP2C19 inhibitor) 

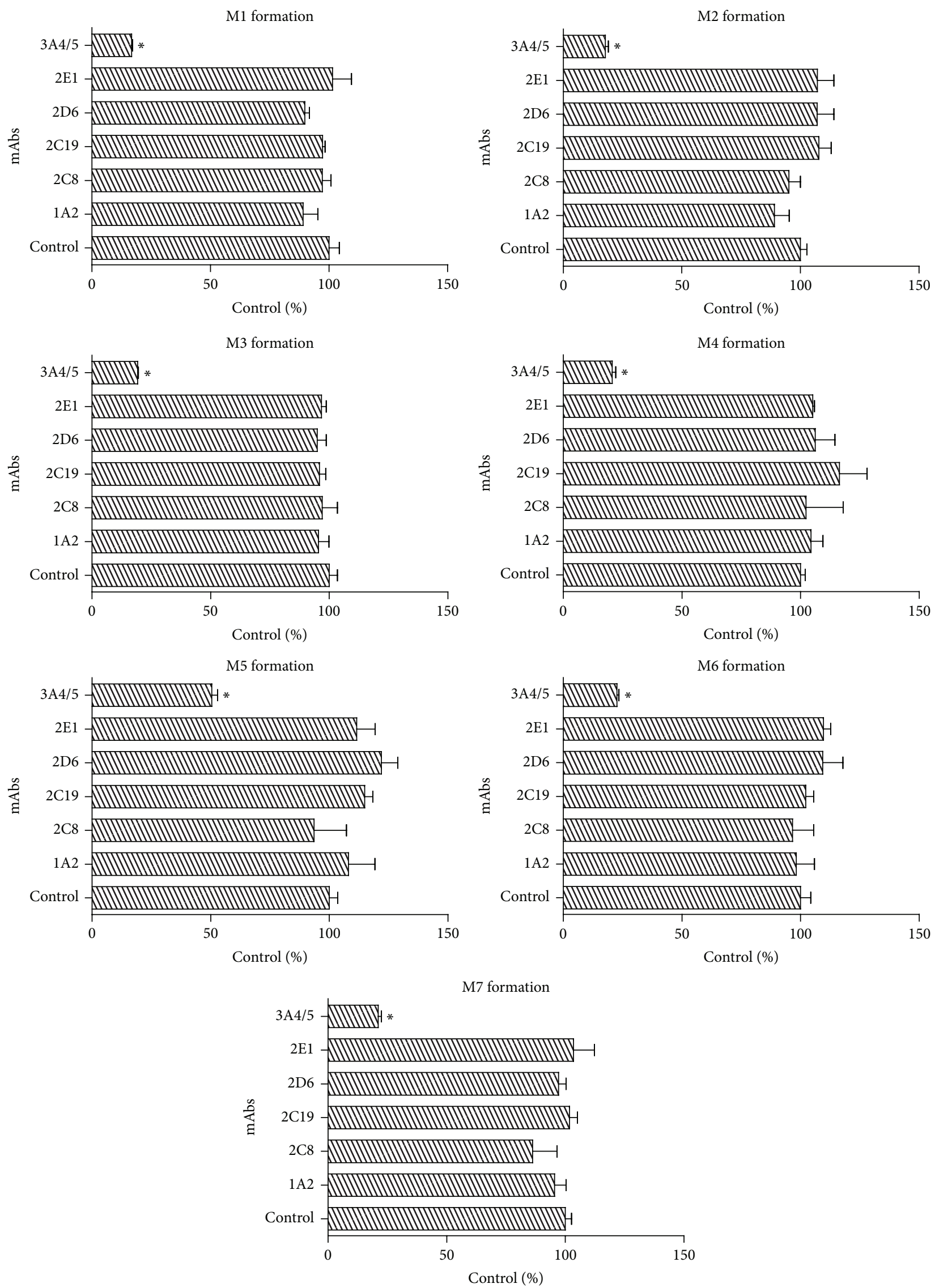

(a)

Figure 3: Continued. 

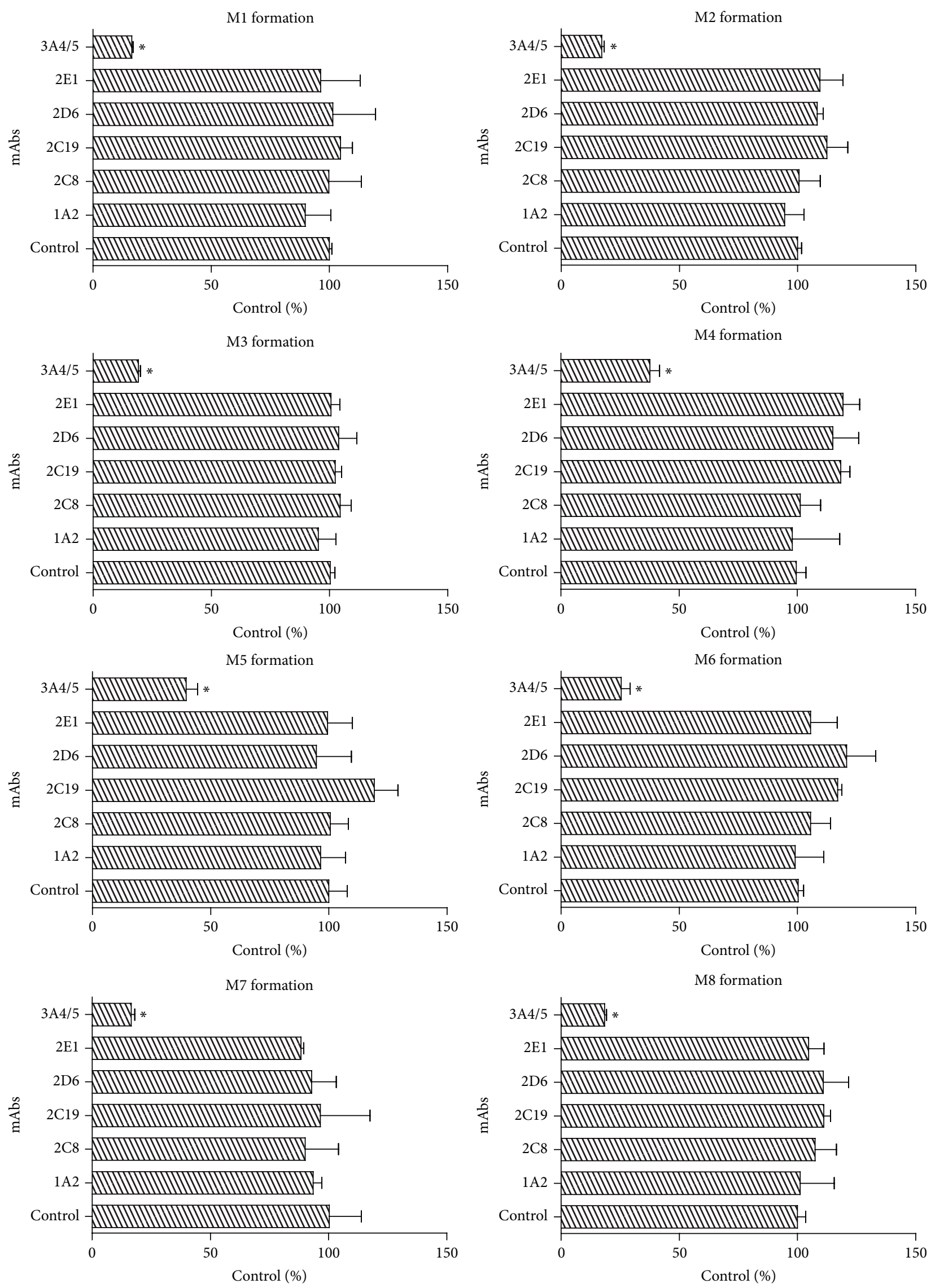

(b)

FIgure 3: Continued. 

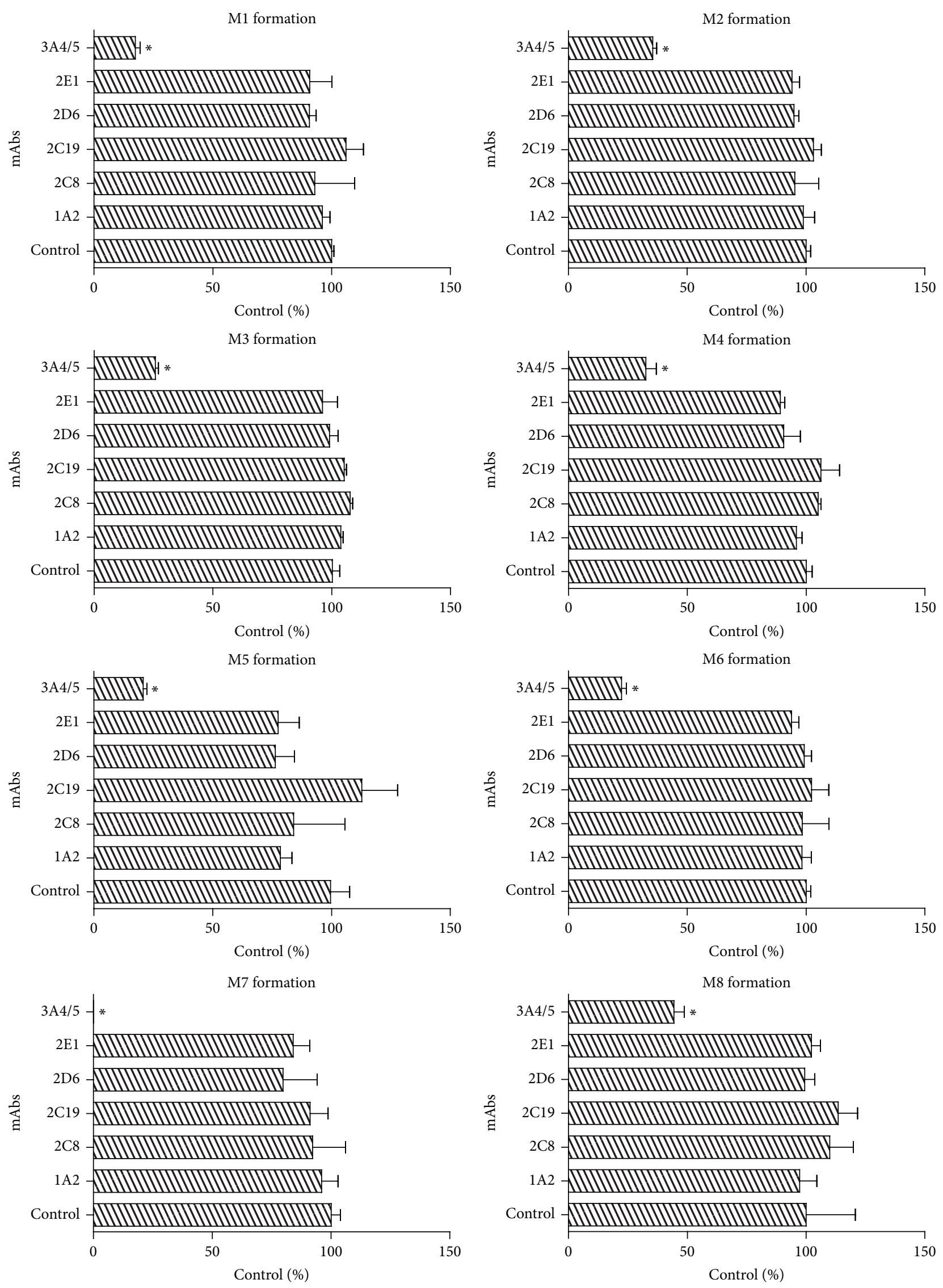

(c)

Figure 3: Continued. 


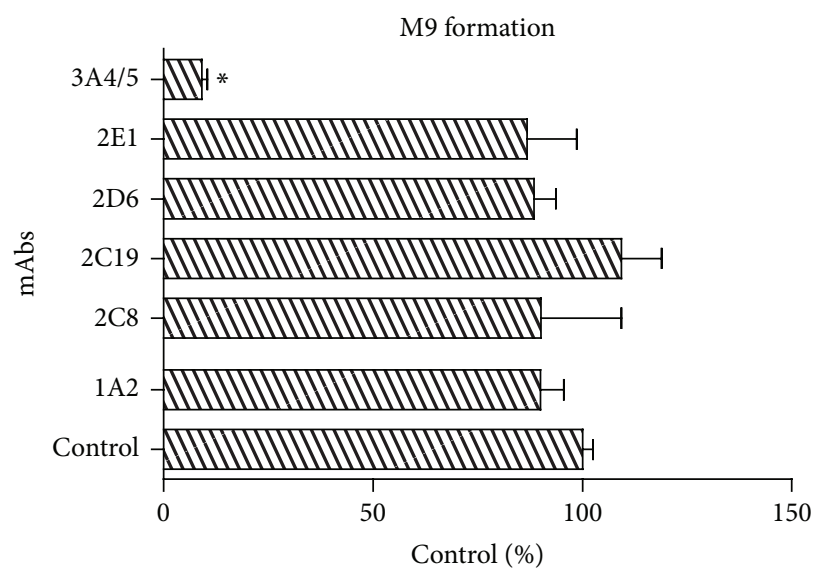

(c)

FIGURE 3: Effects of CYP enzyme mAbs on BAC (a), BMA (b), and BHA (c) metabolism. BAC, BMA, or BHA (10 $\mu$ M) was incubated with HLMs and NADPH-regenerating system in the presence of various individual $\mathrm{mAbs}$ for $120 \mathrm{~min}$ at $37^{\circ} \mathrm{C}$. Equivalent amounts of Tris buffer were used instead of mAbs in the control experiments. Each column represents the mean of three formation rate determinations for the metabolites, and the error bars represent standard deviation of the mean. Statistically significant differences compared with the control $(P<$ $0.05)$ are marked with asterisks $(*)$.

contributed to the formation of M1, M3, M4, M6, M7, and M9. Moreover, the production of M6, M7, and M9 was influenced by fluvoxamine maleate (CYP1A2 inhibitor). According to the results, although several isozymes were involved in BHA metabolism, CYP3A4/5 was still the primary isozyme.

3.20. The Effect of $m A$ bs on Metabolism of BAC, BMA, and $B H A$ in HLMs. Percentage inhibition due to chemical inhibitors is never $100 \%$ and that selectivity is not always significant. Thus, in the next experiment, we used mAbs to further confirm which CYP isozymes mainly contribute to the metabolism of BAC, BMA, and BHA. We added mAbs 15 min prior to NADPH addition to start the reaction and tried to observe the effect of the possible loss of a particular CYP enzyme on the formation of each of the metabolites. As expected, CYP3A4/5 still had the most significant effect and maximally inhibited the metabolite formation compared with the rest of the mAbs (Figure 3). Other mAbs, such as mAb-1A2, mAb-2C8, mAb-2C9, mAb-2C19, mAb-2D6, and $\mathrm{mAb}-2 \mathrm{E} 1$, had no obvious inhibitory effect on the metabolic transformation of BAC, BMA, and BHA. CYP3A4/5 had an extremely important function in the metabolism of BAC, BMA, and BHA.

3.21. Phase I Metabolism of BAC, BMA, and BHA in CDNAExpressed CYP Enzymes. In the next experiments, rather than inhibiting the CYPs, we tried to incubate the compounds with specific cDNA-expressed CYPs bought from BD Life Sciences to reconfirm our chemical inhibitor and monoclonal antibody data. As anticipated, CYP3A4 still had the most significant effect, and 3A5 showed high formation rates for all the metabolites of BAC, BMA, and BHA (Figure 4). And the results indicated that the rate of $\mathrm{BAC}, \mathrm{BMA}$ and $\mathrm{BHA}$ metabolism by CYP 3 A 4 was $32.96 \% \pm 3.51 \%, 19.48 \% \pm 2.02 \%$, and $29.81 \% \pm 3.54 \%$, respectively.

\section{Discussion}

The Chinese medicine Aconitum as toxic drug is commonly used to treat rheumatism and cardiovascular diseases. In addition to efficacy, adverse events of Aconitum poisoning often occur in clinic. Prevention Aconitum toxicity is a key issue for its safe application. Efflux transporters and drugmetabolizing enzymes protect the human body by functioning as the important defense line that limits the invasion of toxicants. In the present study, we have demonstrated that monoester-diterpene alkaloids (MDAs) including BAC, BMA, and BHA were metabolized into several metabolites in HLMs. And CYP3A4 and CYP3A5 were the predominant isozymes responsible for their metabolism by the experiments of chemical inhibitors, mAbs and cDNA-expressed CYP enzymes. A total of 7, 8, and 9 metabolites were found, respectively, when BAC, BMA, or BHA was incubated in the HLMs along with NADPH-regenerating system. A majority of metabolite reaction channels had at least two metabolites, but they did not characterize the exact position of transformation on account of several methyl and hydroxyl groups in the structure of MDAs. What is more, the structures of MDAs are so complex and contain so many similar moieties that it would be extremely difficult to unambiguously identify metabolites solely using mass spectrometry. NMR data would be ideal for such compounds, but it may be difficult to generate sufficient amounts of metabolites. For these reasons, the metabolite characterization of the present study is rather preliminary and speculative, but it may be helpful to understand the metabolic profile of MDAs.

BAC, BMA, and BHA are the main, active and toxic constituents of processed Aconitum. The unprocessed Aconitum is prohibited to sell in the market. Even though the toxicity of BAC, BMA, and BHA is much less than diester diterpene alkaloids [12], attention is still need. The toxic reaction will still occur by excessive absorption of BAC, BMA, 

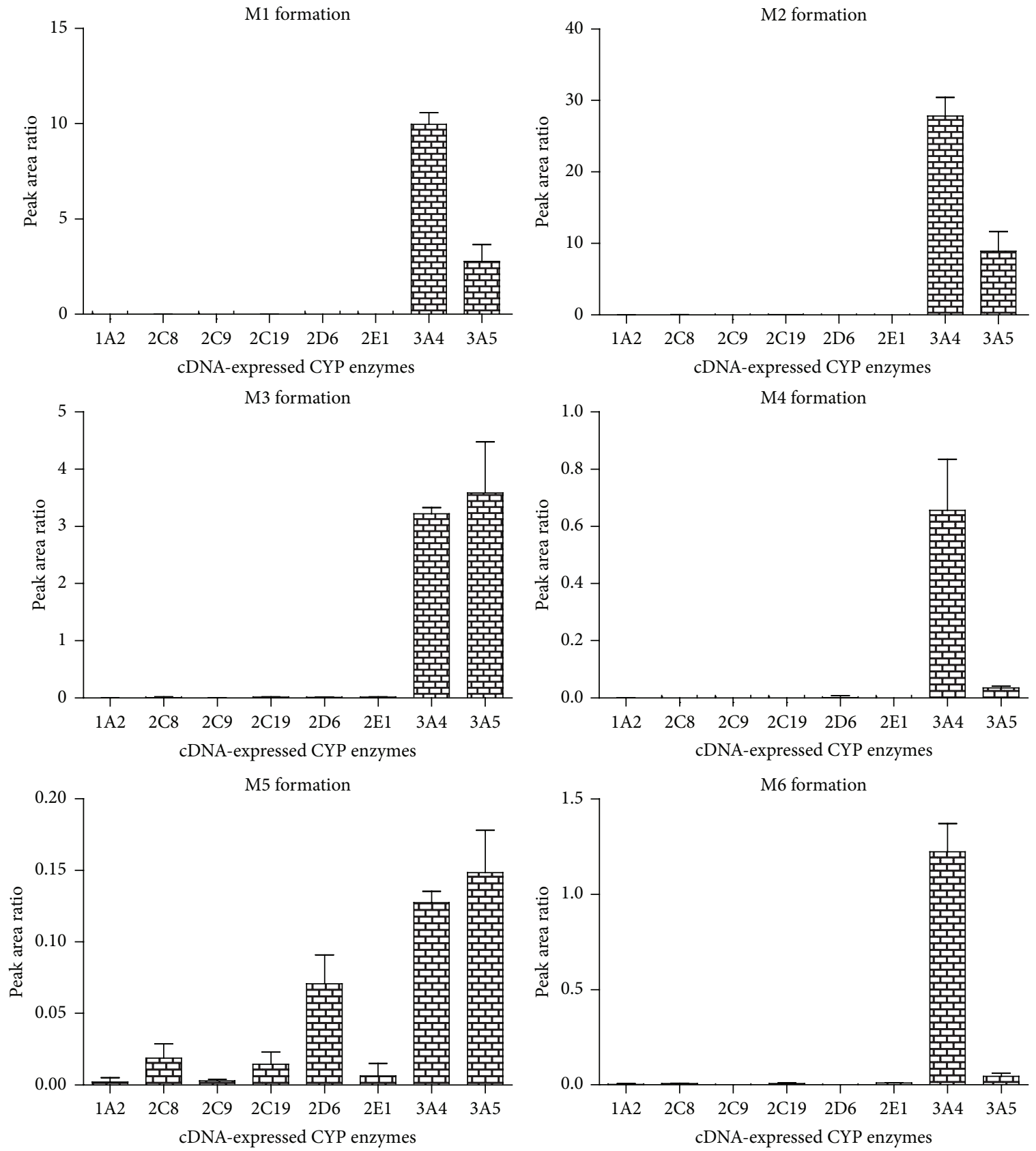

M7 formation

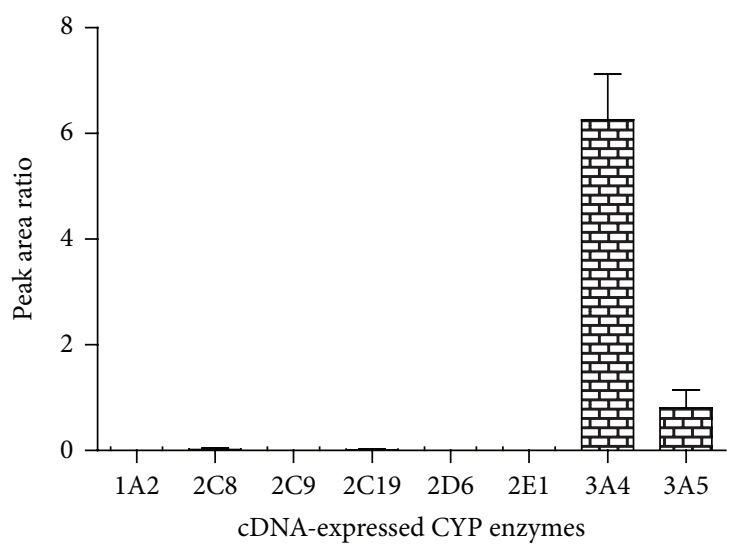

(a)

Figure 4: Continued. 

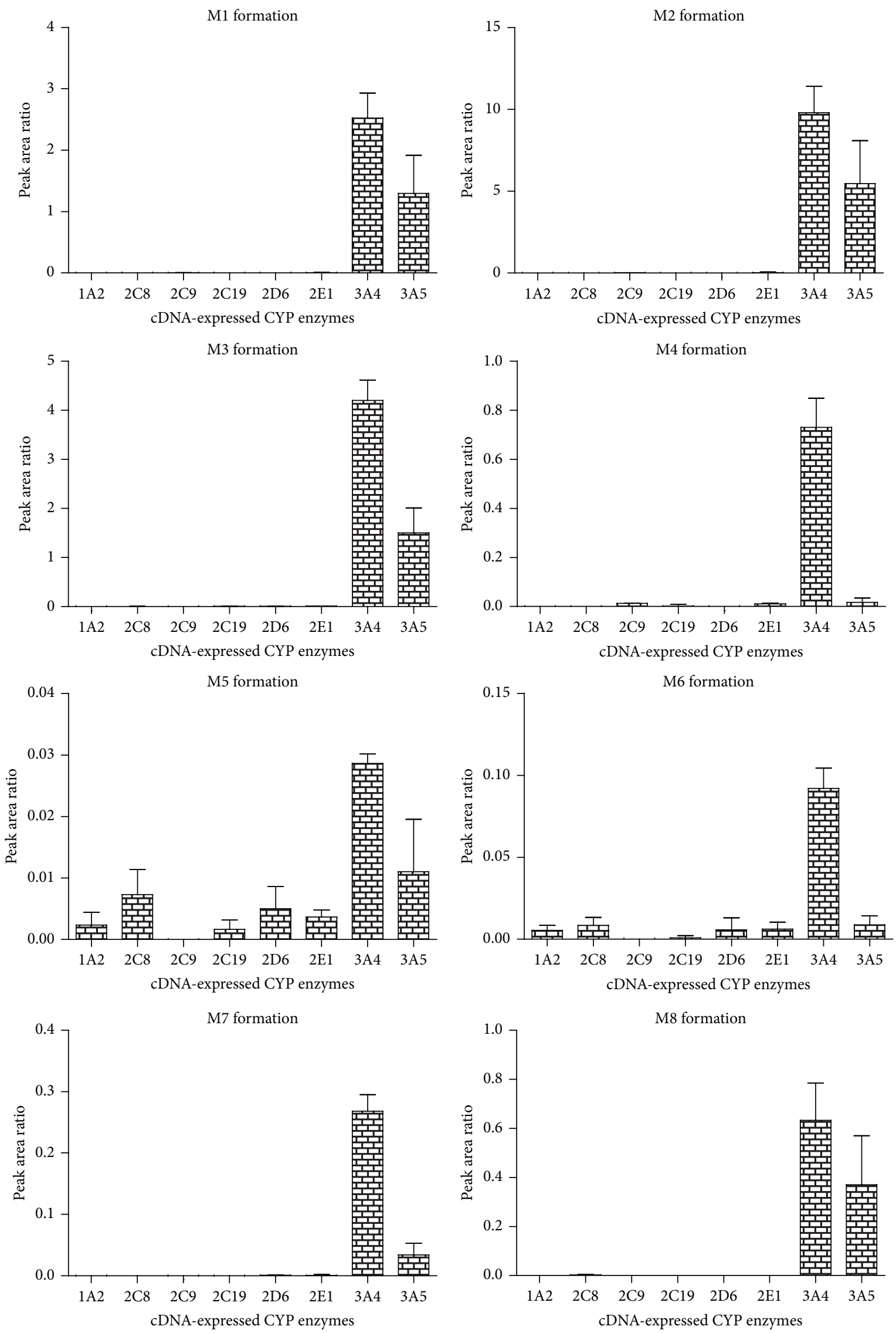

(b)

Figure 4: Continued. 

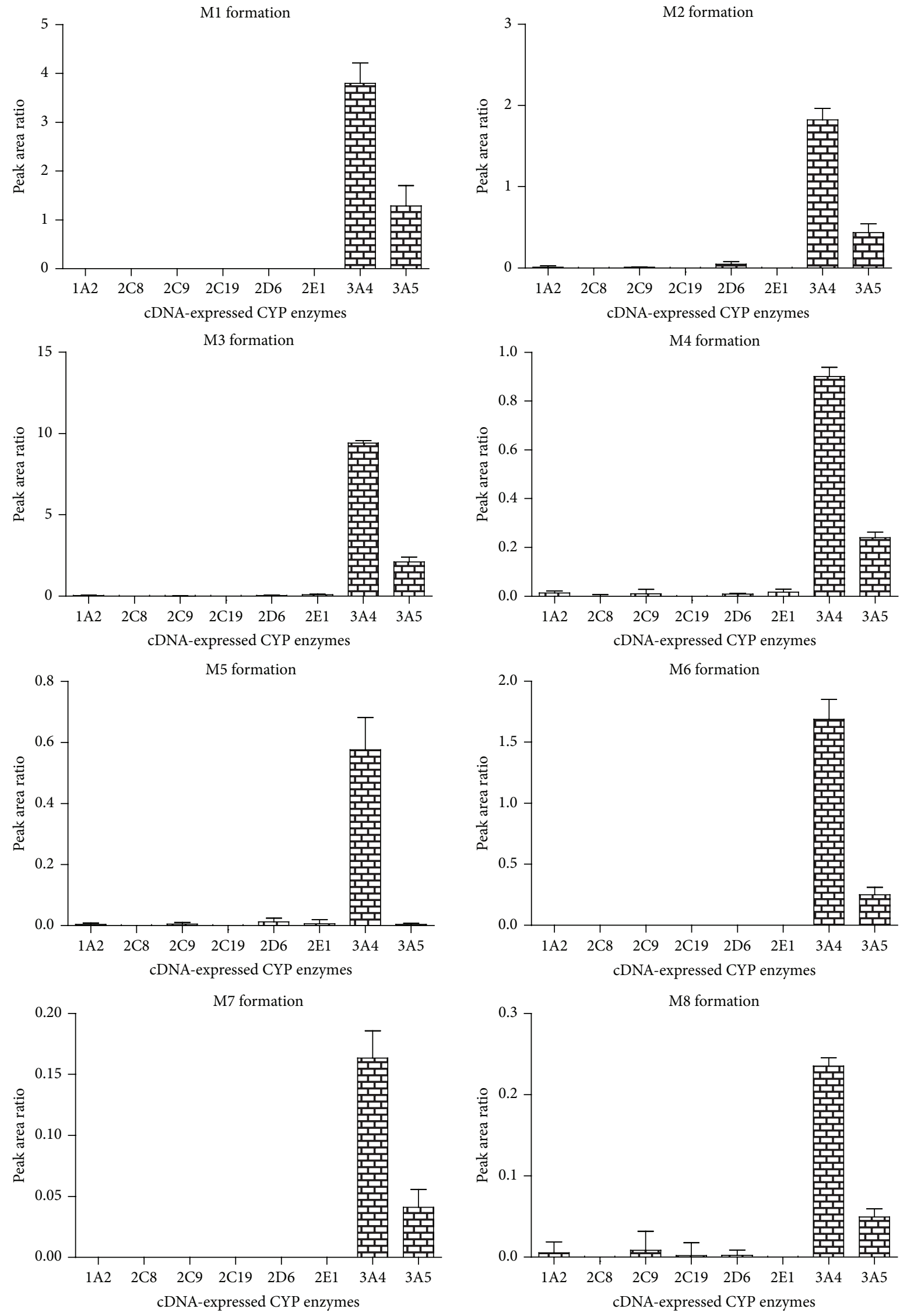

(c)

Figure 4: Continued. 


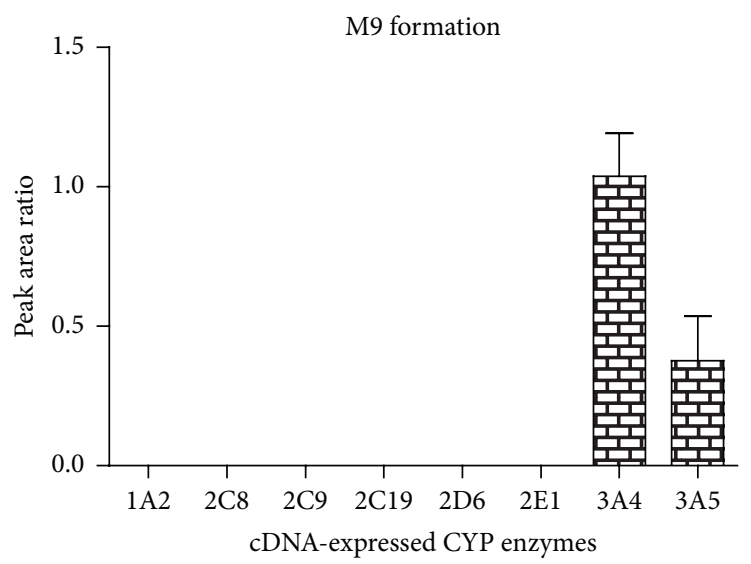

(c)

Figure 4: BAC (a), BMA (b), and BHA (c) metabolism in cDNA-expressed CYP enzymes. BAC, BMA, or BHA (10 $\mu$ M) was incubated with cDNA-expressed CYP enzymes (CYP 1A2, 2C8, 2C9, 2C19, 2D6, 2E1, 3A4, and 3A5) in the presence of NADPH-regenerating system for $120 \mathrm{~min}$ for $37^{\circ} \mathrm{C}$. Data are expressed as the mean of three determinations, and the error bars represent standard deviation of the mean.

and BHA. As is well known, efflux transporters and metabolic enzymes act as the first line to protect the body by limiting the invasion of toxicants. Previous studies indicated that the efflux transporters including P-gp, BCRP, and MRP2 did not mediate the transport of BAC, BMA, and BHA, suggesting that the invasion of $\mathrm{BAC}, \mathrm{BMA}$, and $\mathrm{BHA}$ could not be limited by efflux transporters [11]. In this case, the role of metabolic enzymes in BAC, BMA, and BHA is extremely important.

We investigated the metabolism of BAC, BMA, and BHA for the first time. A total of 7, 8, 9 metabolites were found for BAC, BMA, and BHA in HLMs with NADPHregenerating system (Figure 1). BAC, BMA, and BHA have very similar chemical structures. A methyl moiety attaches to the nitrogen atom and a hydroxyl group links to position $\mathrm{C} 3$ in the structure of MA, whereas the unit attached to the nitrogen is ethyl in the BAC structure. The group linked to the nitrogen atom in the structure of BHA is methyl, but the hydroxyl moiety at position C3 is not observed. Therefore, their metabolic pathways were also similar, including demethylation, dehydrogenation, demethylationdehydrogenation, hydroxylation, and didemethylation (Figure 5). What is more, these metabolic pathways were similar to those of DDAs [19-21]. Previous studies indicated that HA could be metabolized into MA by the effect of CYP enzymes. As expected, BHA was also metabolized into BMA in the present study. It was reported that the high toxicity of Aconitum alkaloids was due to the acetyl group at $\mathrm{C} 8$, the hydroxyl group at $\mathrm{C} 13$, four methoxyl groups at $\mathrm{C} 1, \mathrm{C} 6, \mathrm{C} 16$, and $\mathrm{C} 18$, and the benzoyl ester group at $\mathrm{C} 14$ [9], meaning that the loss of these groups will decrease the compound's toxicity. According to our results, all the metabolites (except for the hydroxylation metabolite) were either loss of methyl from methoxyl group or dehydrogenation from hydroxyl group, indicating that their toxicology was less than that of the parent compound.
The results showed that CYP enzymes mediated the metabolism of BAC, BMA, and BHA, reducing the accumulation of toxic parent compound in the body. In the next experiments, we further investigated which CYP isozymes are responsible for their metabolism. The targeted isozymes included CYP1A2, 2C8, 2C9, 2C19, 2D6, 2E1, 3A4, and 3A5, because up to $90 \%$ of human drug metabolism may be attributed to these eight enzymes. In the chemical inhibitors experiments, the major hepatic enzyme responsible for the metabolism of BAC, BMA, and BHA was identified as CYP3A4/5, while chemicals selective for CYP2C8, CYP2C9, and CYP2C19 made a minor effect on their formations. It was assumed that a selective chemical inhibitor raised against a human CYP isoform at high concentration, which was more than the Ki value, will cross-react with other CYP isozymes. For example, recent studies suggest that omeprazole is a substrate probe for CYP2C19, however in vitro studies show that omeprazole could be metabolized by CYP3A4 in the same way [30]. As is well known, the chemical inhibitors are never $100 \%$ and their selectivity is not always great. Hence, we used mAbs experimental approach to reconfirm our results. We demonstrated that antibody against human CYP3A4/5 was the most potent and inhibited the formation of BAC, BMA, and BHA. Furthermore, the experiment of cDNAexpressed CYP enzymes showed that CYP3A4 and CYP3A5 were the major isozymes for the metabolism of BAC, BMA, and BHA, and the BAC metabolite M5 generated by CYP2D6, and the BMA metabolites M5 and M6 generated by CYP2C8, 2D6, and 3E1 supported the minimal roles of these enzymes. However, the inhibition experiments of BAC, BMA, and BHA did not support that CYP2C8, 2D6, and 3E1 were the subordinate enzymes which mediated the biotransformation of BAC, BMA, and BHA. Taken together, the results of cDNA-expressed CYP enzymes, chemical inhibitors, and mAbs experiments, we come to the conclusion that CYP3A4 


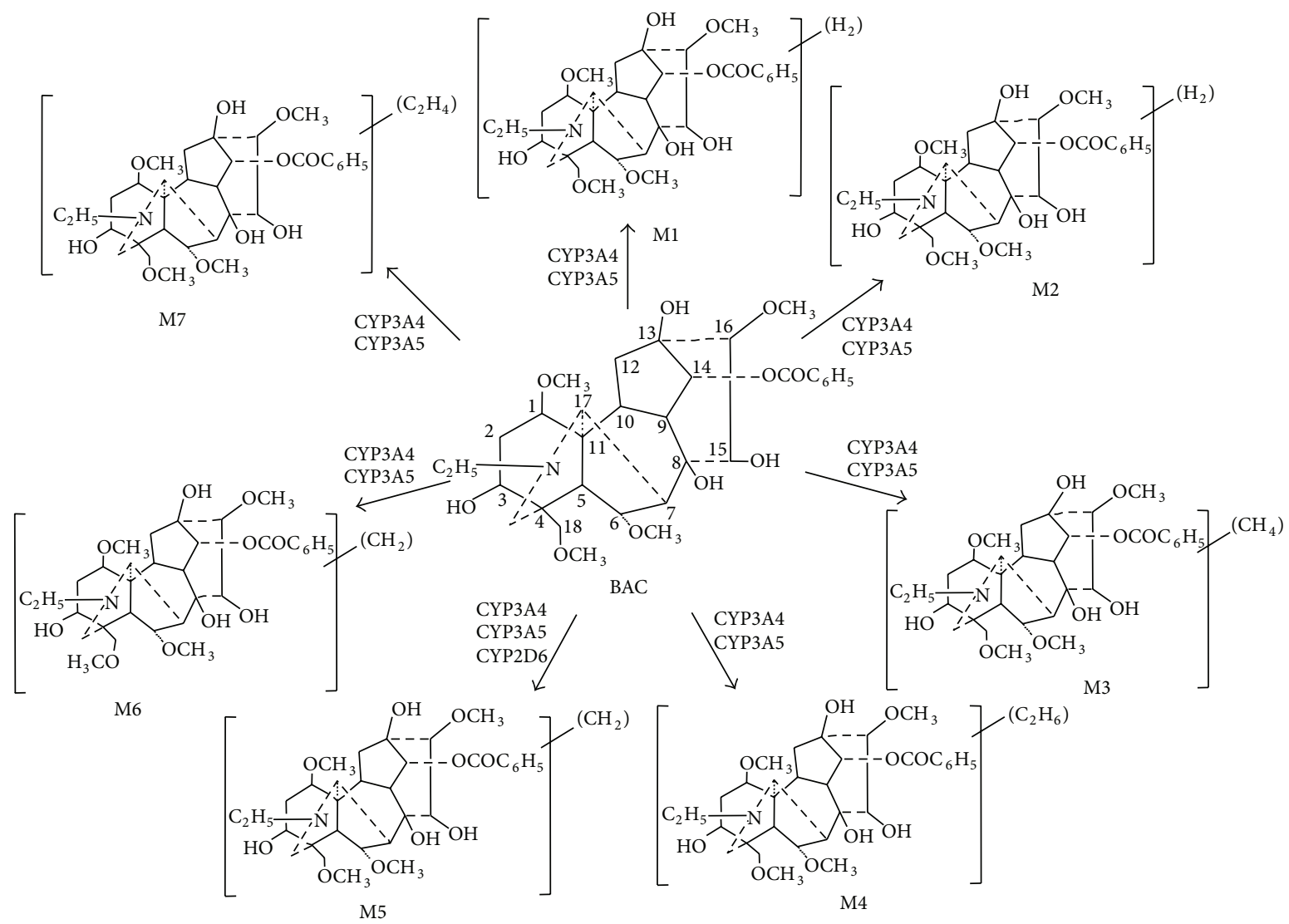

(a)
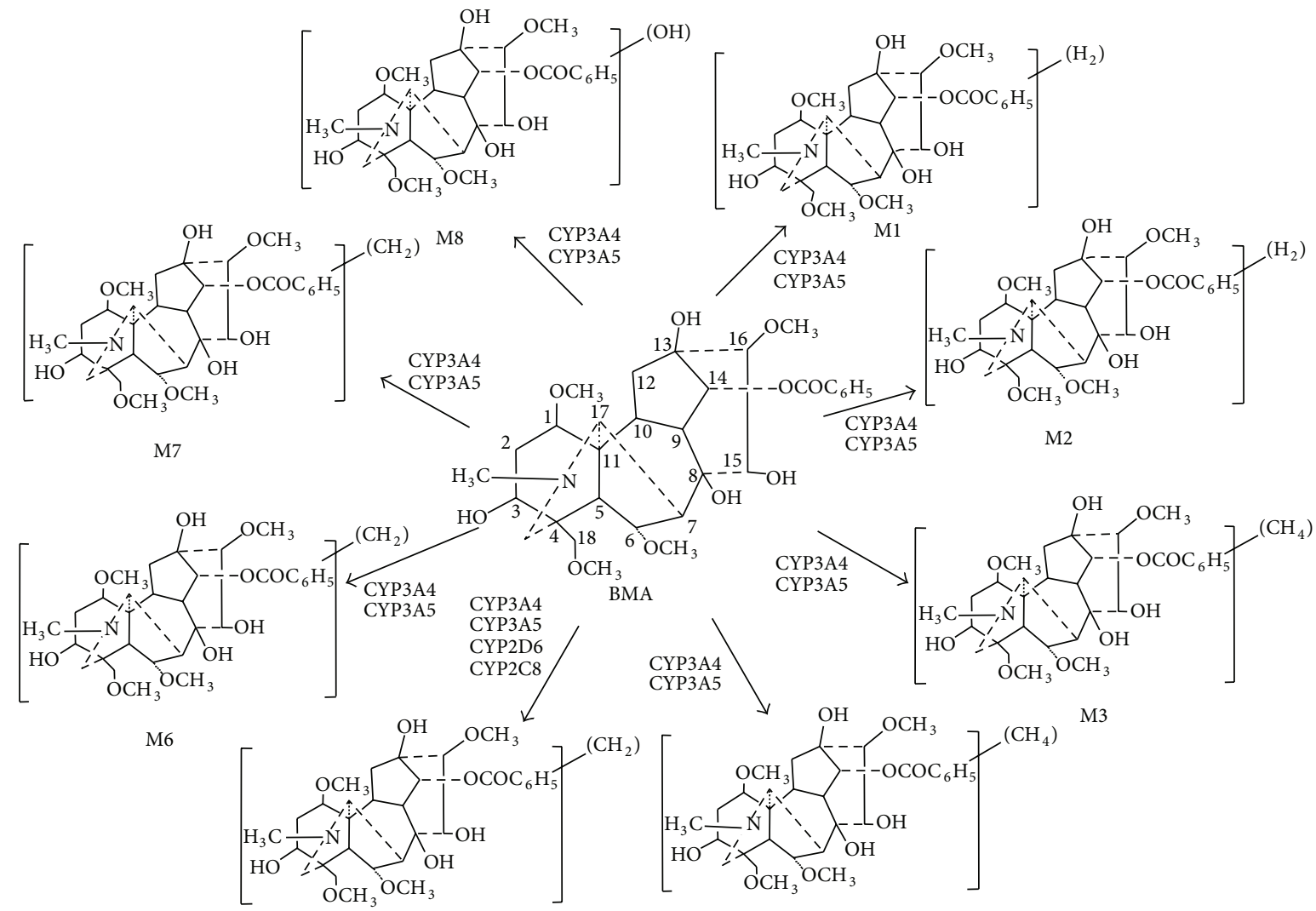

M5

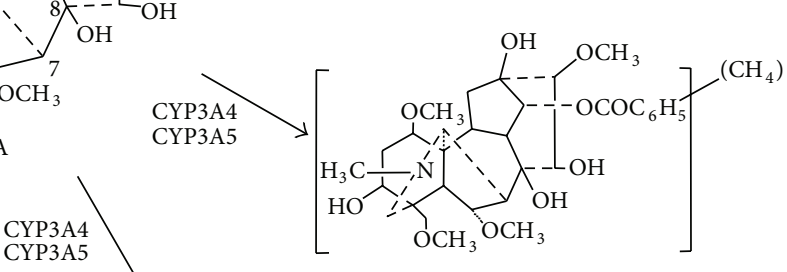

$\searrow \quad \mathrm{OH} \quad \mathrm{OCH}_{3} \quad \mathrm{M} 3$

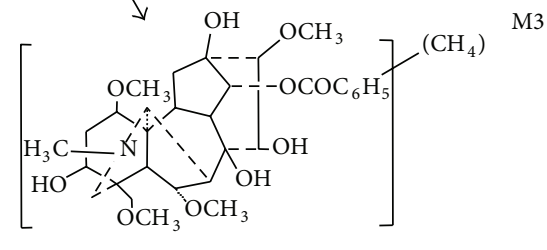

Figure 5: Continued. 


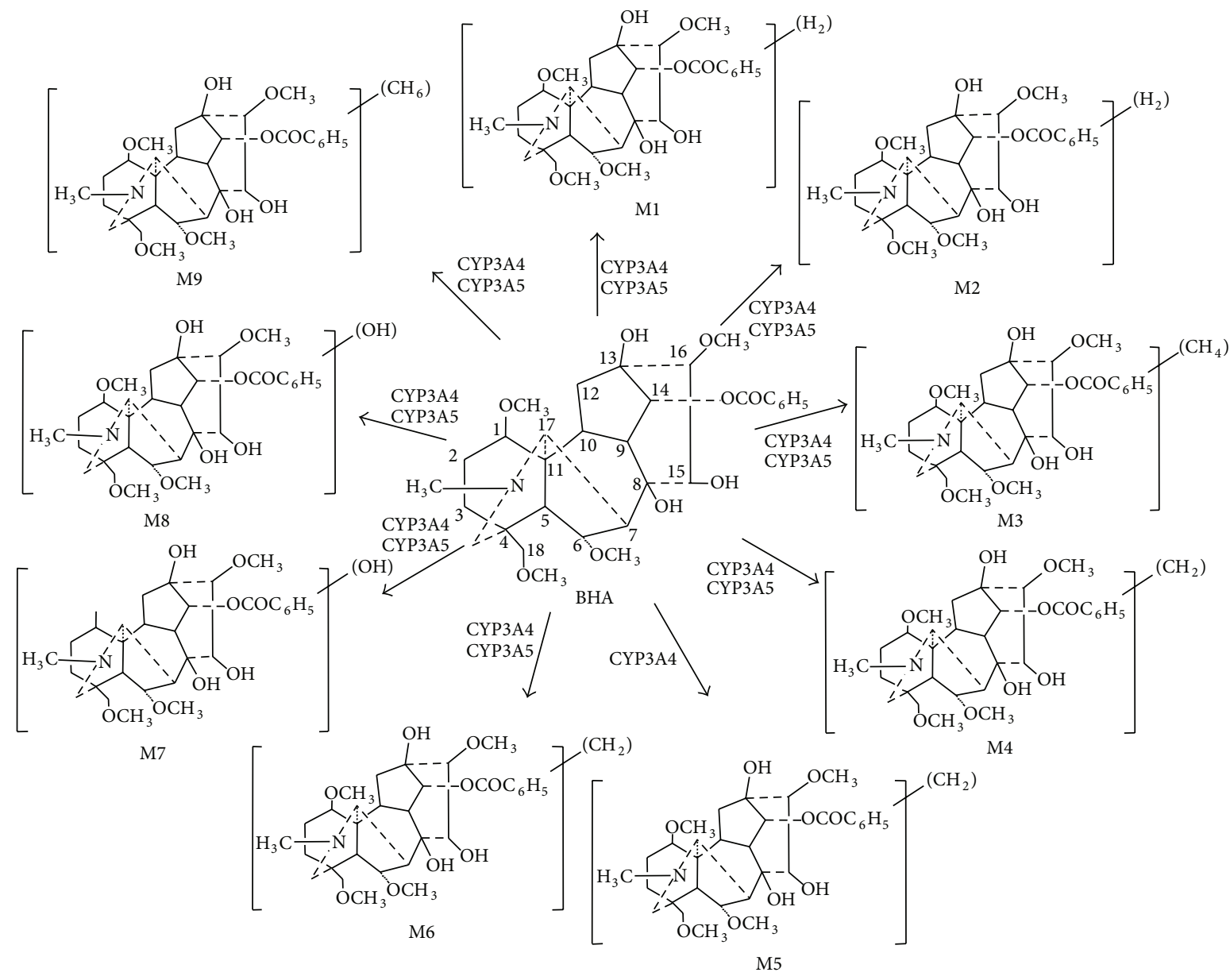

(c)

FIgURE 5: Proposed metabolic pathways of BAC (a), BMA (b), and BHA (c) in HLMs and CYP isozymes involved in their metabolism.

and CYP3A5 were the major isozymes responsible for the metabolism of BAC, BMA, and BHA (Figure 5).

CYP3A4 and CYP3A5 also contributed a great role to the metabolism of DDAs (AC, MA, and HA) [11, 20, 31]. DDAs could not be only chemically hydrolyzed into MDAs, but also biologically hydrolyzed $[2,15]$. In other words, after the intake of processed Aconitum, three kinds of behavior will occur: DDAs transformed into less toxic metabolites by CYP3A4 and CYP3A5; MDAs transformed into less toxic metabolites by CYP3A4 and CYP3A5; and DDAs transformed into MDAs by the esterase, which will greatly reduce the toxicity of Aconitum. Therefore, protection or promotion of CYP3A function could prevent excessive Aconitum absorbed into the bloodstream, thereby avoiding toxic reactions.

CYP3A is one of the most important CYP isoform responsible for drug metabolism by humans, because it is highly expressed in critical tissues such as the gastrointestinal tract and liver, and it is involved in the oxidative biotransformation of numerous clinically useful therapeutic agents. However, many factors could regulate CYP3A expression and activity [32]. Accordingly, the potential for drug interactions with these drugs as well as other CYP3A substrates, when given concomitantly, is high. Metabolism involving CYP3A is also likely to be affected by liver disease as well as aging. Therefore, more attention should be paid when we ingest Aconitum, even though the CYP enzymes could act as a defense line to decrease its toxicity.

\section{Abbreviations}

MDAs: Monoester-diterpene alkaloids

DDAs: Diester-diterpene alkaloids

AC: Aconitine

MA: Mesaconitine

HA: Hypaconitine

BAC: Benzoylaconine

BMA: Benzoylmesaconine

BHA: Benzoylhypaconine

HLMs: Human liver microsomes

mAbs: Monoclonal antibodies

NADP: $\quad \beta$-nicotinamide adenine dinucleotide phosphate

6-P-G: Glucose-6-phosphate

PDH: Glucose-6-phosphate dehydrogenase 


$\begin{array}{ll}\text { P-gp: } & \text { P-glycoprotein } \\ \text { BCRP: } & \text { Breast cancer resistance protein } \\ \text { MRP2: } & \text { Multidrug resistance-associated protein 2 } \\ \text { LC-MS/MS: } & \begin{array}{l}\text { Liquid chromatography-tandem mass } \\ \text { spectrometry }\end{array} \\ \text { CYP450: } & \text { Cytochrome P450 } \\ \text { Ki: } & \text { Kinetic inhibition rate constants } \\ \text { UPLC: } & \text { Ultraperformance Liquid-Chromtography } \\ \text { NMR: } & \text { Nuclear magnetic resonance. }\end{array}$

\section{Conflict of Interests}

The authors declare that no conflict of interests exists.

\section{Authors' Contribution}

Ling Ye and Xiao-Shan Yang contributed equally to this work.

\section{Acknowledgments}

This work was supported in part by the Key International Joint Research Project of the National Natural Science Foundation of China (no. 81120108025), the National Basic Research Program of China (973 Program, 2009CB5228008), and the International Science and Technology Cooperation Base (Grant no. 2010JD035).

\section{References}

[1] Y. Suzuki, T. Oyama, A. Ishige et al., "Antinociceptive mechanism of the aconitine alkaloids mesaconitine and benzoylmesaconine," Planta Medica, vol. 60, no. 5, pp. 391-394, 1994.

[2] K. Wada, M. Nihira, H. Hayakawa, Y. Tomita, M. Hayashida, and Y. Ohno, "Effects of long-term administrations of aconitine on electrocardiogram and tissue concentrations of aconitine and its metabolites in mice," Forensic Science International, vol. 148, no. 1, pp. 21-29, 2005.

[3] X. Tang, P. Song, and A. Ou, "Documentation system evaluations of the clinical security use of Aconitum," Journal of New Chinese Medicine, vol. 40, no. 4, pp. 95-97, 2008.

[4] N. G. Bisset, "Arrow poisons in China. Part II. Aconitumbotany, chemistry, and pharmacology," Journal of Ethnopharmacology, vol. 4, no. 3, pp. 247-336, 1981.

[5] S. Singh, P. P. Fadnis, and B. K. Sharma, "Aconite poisoning," The Journal of the Association of Physicians of India, vol. 34, no. 11, pp. 825-826, 1986.

[6] A. A. van Landeghem, E. A. de Letter, W. E. Lambert, C. H. van Peteghem, and M. H. A. Piette, "Aconitine involvement in an unusual homicide case," International Journal of Legal Medicine, vol. 121, no. 3, pp. 214-219, 2007.

[7] S. P. Elliott, "A case of fatal poisoning with the aconite plant: quantitative analysis in biological fluid," Science and Justice, vol. 42, no. 2, pp. 111-115, 2002.

[8] M. Fu, M. Wu, Y. Qiao, and Z. Wang, "Toxicological mechanisms of Aconitum alkaloids," Pharmazie, vol. 61, no. 9, pp. 735741, 2006.

[9] A. Ameri, "The effects of Aconitum alkaloids on the central nervous system," Progress in Neurobiology, vol. 56, no. 2, pp. 211235, 1998.
[10] T. Y. K. Chan, "Aconite poisoning presenting as hypotension and bradycardia," Human and Experimental Toxicology, vol. 28, no. 12, pp. 795-797, 2009.

[11] L. Ye, X. Yang, Z. Yang et al., "The role of efflux transporters on the transport of highly toxic aconitine, mesaconitine, hypaconitine, and their hydrolysates, as determined in cultured Caco-2 and transfected MDCKII cells," Toxicology Letters, vol. 216, pp. 86-99, 2012.

[12] J. Singhuber, M. Zhu, S. Prinz, and B. Kopp, “Aconitum in traditional Chinese medicine-a valuable drug or an unpredictable risk?" Journal of Ethnopharmacology, vol. 126, no. 1, pp. 18-30, 2009.

[13] X.-X. Liu and R.-B. Chao, "Determination of alkaloids in Radix Aconiti Lateralis Preparata by RP-ion-pair HPLC," Yaoxue Xuebao, vol. 41, no. 4, pp. 365-369, 2006.

[14] M. Mizugaki, K. Ito, Y. Ohyama, Y. Konishi, S. Tanaka, and K. Kurasawa, "Quantitative analysis of Aconitum alkaloids in the urine and serum of a male attempting suicide by oral intake of aconite extract," Journal of Analytical Toxicology, vol. 22, no. 4, pp. 336-340, 1998.

[15] L. Ye, S. Gao, Q. Feng et al., "Development and validation of a highly sensitive UPLC-MS/MS method for simultaneous determination of aconitine, mesaconitine, hypaconitine, and five of their metabolites in rat blood and its application to a pharmacokinetics study of aconitine, mesaconitine, and hypaconitine," Xenobiotica, vol. 42, no. 6, pp. 518-525, 2012.

[16] M. Kobayashi, K. Mori, H. Kobayashi, R. B. Pollard, and F. Suzuki, "The regulation of burn-associated infections with herpes simplex virus type 1 or Candida albicans by a non-toxic aconitine-hydrolysate, benzoylmesaconine. Part 1: antiviral and anti-fungal activities in thermally injured mice," Immunology and Cell Biology, vol. 76, no. 3, pp. 202-208, 1998.

[17] R. C. Baselt, "Disposition of toxic drugs and chemicals in man," 2008.

[18] A. C. Moffat, M. D. Osselton, B. Widdop, and J. Watts, Eds., Clarke's Analysis of Drugs and Poisons, Pharmaceutical Press, London, UK.

[19] L. Tang, L. Ye, C. Lv, Z. Zheng, Y. Gong, and Z. Liu, "Involvement of CYP3A4/5 and CYP2D6 in the metabolism of aconitine using human liver microsomes and recombinant CYP450 enzymes," Toxicology Letters, vol. 202, no. 1, pp. 47-54, 2011.

[20] L. Ye, L. Tang, Y. Gong et al., "Characterization of metabolites and human $\mathrm{P} 450$ isoforms involved in the microsomal metabolism of mesaconitine," Xenobiotica, vol. 41, no. 1, pp. 4658, 2011.

[21] L. Ye, T. Wang, C. Yang et al., "Microsomal cytochrome P450mediated metabolism of hypaconitine, an active and highly toxic constituent derived from Aconitum species," Toxicology Letters, vol. 204, no. 1, pp. 81-91, 2011.

[22] Y. Kinoshita, N. Matsumoto, M. Watanabe et al., "Comparison of the effects of omeprazole and rabeprazole on ticlopidine metabolism in vitro," Journal of Pharmacological Sciences, vol. 117, no. 1, pp. 19-26, 2011.

[23] T. Kadokura, M. den Adel, W. J. J. Krauwinkel, T. Takeshige, and A. Nishida, "The effect of fluvoxamine on the pharmacokinetics, safety, and tolerability of ramosetron in healthy subjects," European Journal of Clinical Pharmacology, vol. 64, no. 7, pp. 691-695, 2008.

[24] J. Schmider, D. J. Greenblatt, S. M. Fogelman, L. L. von Moltke, and R. I. Shader, "Metabolism of dextromethorphan in vitro: 
involvement of cytochromes P450 2D6 and 3A3/4, with a possible role of 2E1.," Biopharmaceutics \& Drug Disposition, vol. 18, pp. 227-240, 1997.

[25] D. F. McGinnity, J. Tucker, S. Trigg, and R. J. Riley, "Prediction of CYP2C9-mediated drug-drug interactions: a comparison using data from recombinant enzymes and human hepatocytes," Drug Metabolism and Disposition, vol. 33, no. 11, pp. 1700-1707, 2005.

[26] M. J. Karjalainen, P. J. Neuvonen, and J. T. Backman, "Rofecoxib is a potent, metabolism-dependent inhibitor of CYP1A2: implications for in vitro prediction of drug interactions," Drug Metabolism and Disposition, vol. 34, no. 12, pp. 2091-2096, 2006.

[27] K. Kobayashi, K. Urashima, N. Shimada, and K. Chiba, "Selectivities of human cytochrome p450 inhibitors toward rat p450 isoforms: study with cDNA-expressed systems of the rat," Drug Metabolism and Disposition, vol. 31, no. 7, pp. 833-836, 2003.

[28] F. F. Y. Radwan and J. S. Ramsdell, "Characterization of in vitro oxidative and conjugative metabolic pathways for brevetoxin (PbTx-2)," Toxicological Sciences, vol. 89, no. 1, pp. 57-65, 2006.

[29] K. Levová, M. Moserová, V. Kotrbová et al., "Role of cytochromes $\mathrm{P} 450$ 1A1/2 in detoxication and activation of carcinogenic aristolochic acid I: studies with the hepatic NADPH: cytochrome P450 reductase null (HRN) mouse model," Toxicological Sciences, vol. 121, no. 1, pp. 43-56, 2011.

[30] R. Yuan, S. Madani, X.-X. Wei, K. Reynolds, and S.-M. Huang, "Evaluation of cytochrome p450 probe substrates commonly used by the pharmaceutical industry to study in vitro drug interactions," Drug Metabolism and Disposition, vol. 30, no. 12, pp. 1311-1319, 2002.

[31] Z. Yang, S. Gao, J. Wang et al., "Enhancement of oral bioavailability of 20(S)-ginsenoside Rh2 through improved understanding of its absorption and efflux mechanisms," Drug Metabolism and Disposition, vol. 39, no. 10, pp. 1866-1872, 2011.

[32] L. Wojnowski, "Genetics of the variable expression of CYP3A in humans," Therapeutic Drug Monitoring, vol. 26, no. 2, pp. 192199, 2004. 


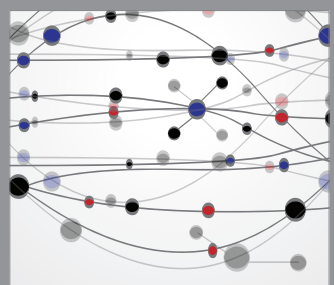

The Scientific World Journal
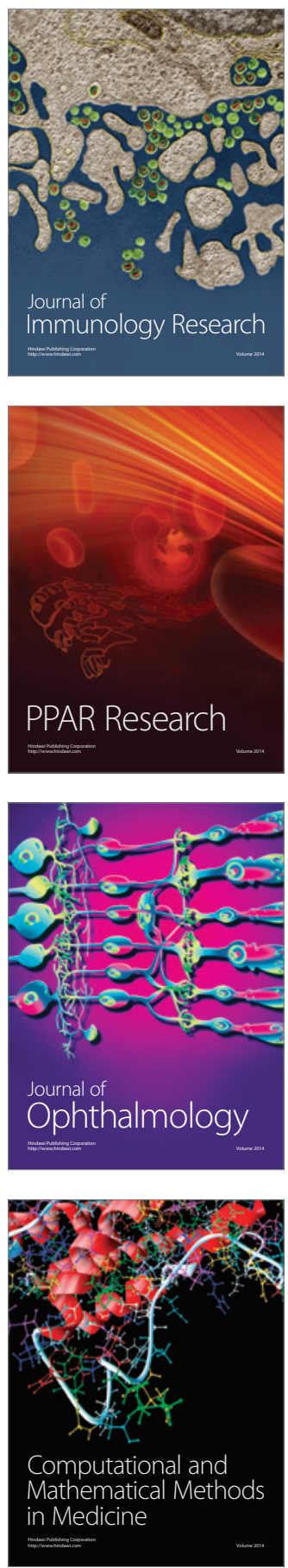

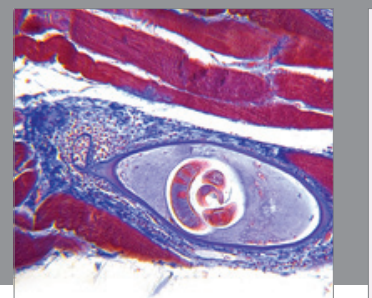

Gastroenterology

Research and Practice
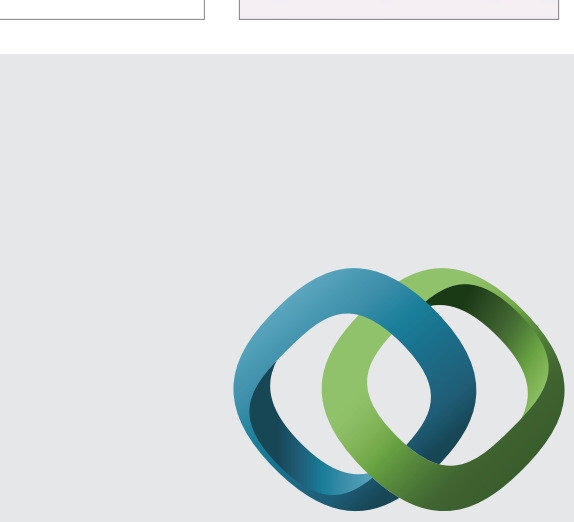

\section{Hindawi}

Submit your manuscripts at

http://www.hindawi.com
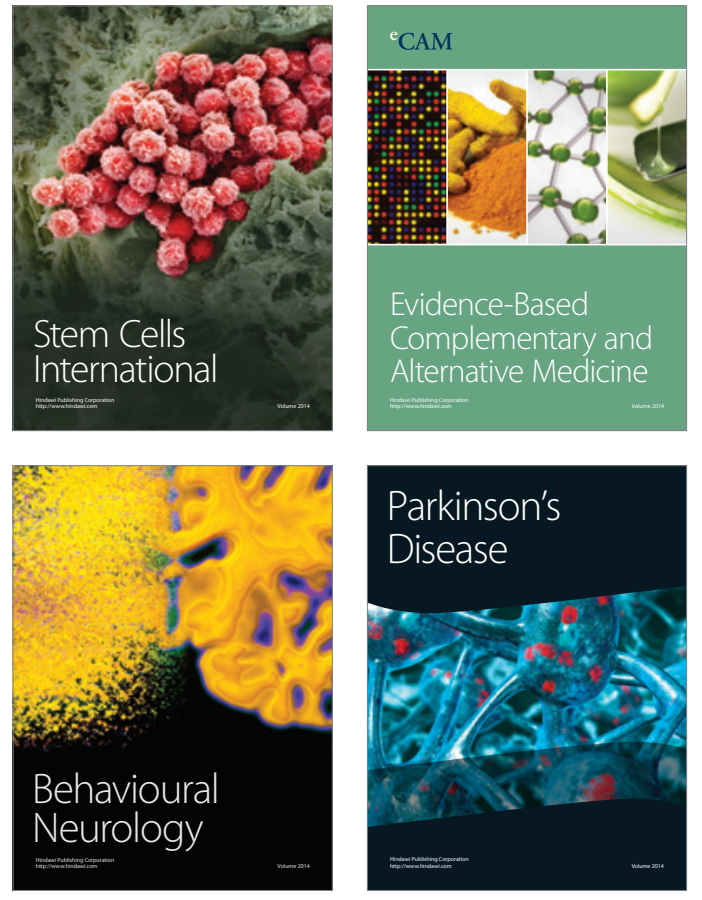
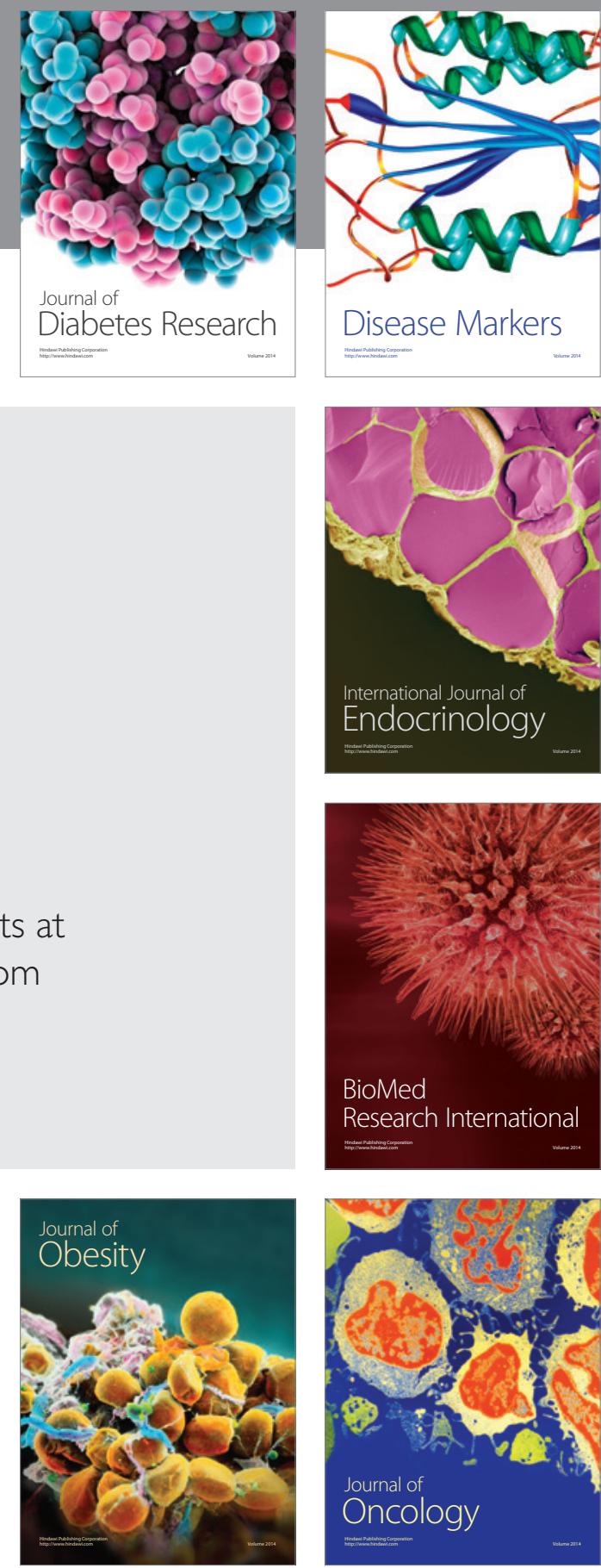

Disease Markers
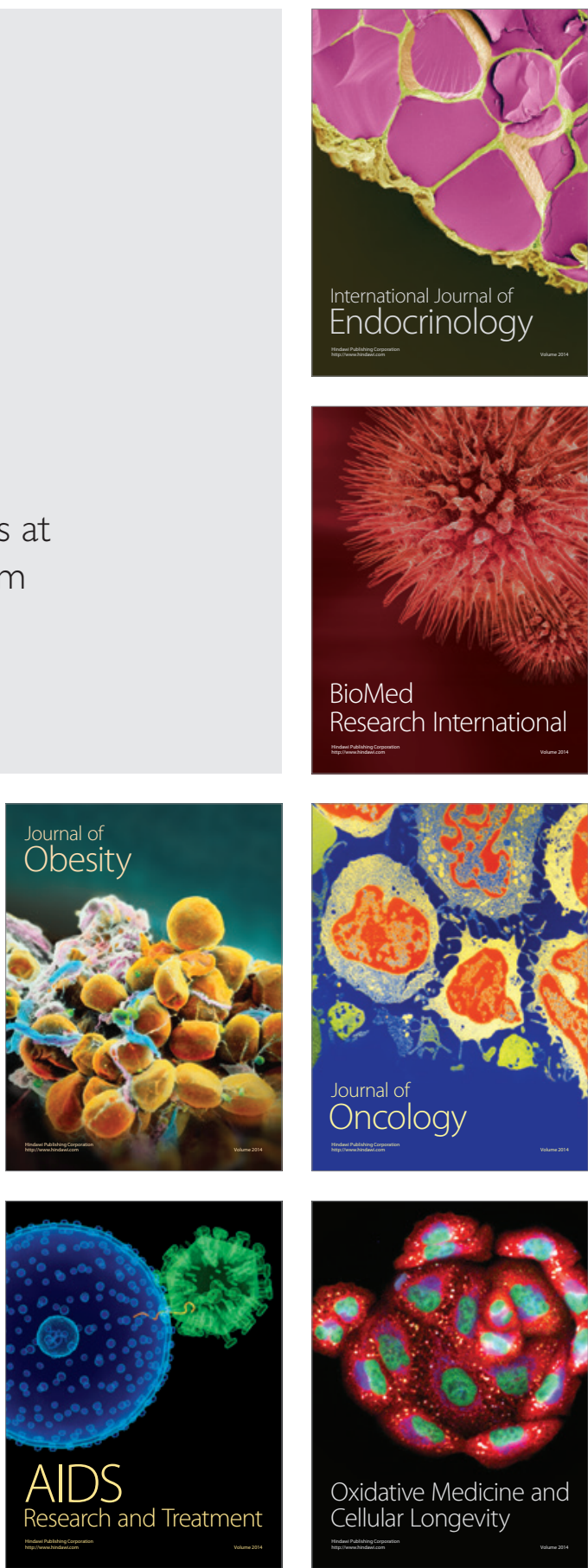